\title{
LAS LETTERS DE JOHN TALBOT DILLON (1781) Y EL ESSAI SUR LA LITTÉRATURE ESPAGNOLE (1810) EN LOS INICIOS DE LA HISTORIOGRAFÍA LITERARIA ESPAÑOLA
}

\author{
Manuel Contreras Jiménez \\ (Universidad de Sevilla) \\ manuelcontreras95sev@gmail.com
}

\begin{abstract}
RESUMEN: Thomasina Ross advertía ya en 1823 que el Essai sur la littérature espagnole (1810), era un «gross plagiarism» de las Letters from an English traveller... (1781) de John Talbot Dillon. El presente artículo analiza la relación textual entre ambas obras, enmarcándolas en los orígenes de la historiografía literaria española. A través de una exploración de las diversas fuentes nacionales (en especial los Orígenes de Velázquez, 1754) y extranjeras utilizadas por Dillon y el autor del Essai, también se ofrecen conclusiones al respecto de: 1) cómo nacen y evolucionan las primeras historias de la literatura española en un constante diálogo que superó nuestras fronteras; 2) cómo a principios del XIX la imagen de España y su literatura vive un importante cambio en el que destacaron los viajeros británicos desde el último tercio del siglo XVIII, y el propio Dillon en particular.

PALABRAS ClAVE: John Talbot Dillon, Malmontais, Historiografía literaria española, Viajeros, Canon.
\end{abstract}

\section{JOHN TALBOT DILLON'S LETTERS (1781) AND THE ESSAI SUR LA LITTÉRATURE ESPAGNOLE (1810) IN THE BEGINNING OF SPANISH LITERARY HISTORIOGRAPHY}

ABSTRACT: Thomasina Ross had already noticed in 1823 that the anonymous Essai sur la littérature espagnole (1810) was a «gross plagiarism» of John Talbot Dillon's Letters from an English traveller... (1781). This article analyses the textual connection between both texts and it places them in the beginning of Spanish literary historiography. A research on the different national (particularly Velázquez's Orígenes, 1754) and foreign sources used by Dillon and the Essai's author is also delivered, presenting some conclusions regarding to: 1) the origin and evolution of the histories of Spanish literature in their transnational dialogue context; 2) the image of Spain and its literature in $18^{\text {th }}$-century Europe, and how it changes around the beginning of $19^{\text {th }}$ century; a process in which English travellers - and specially Dillon himself - had an important impact from the 70s.

KEYWORDS: John Talbot Dillon, Malmontais, Spanish literary historiography, Travellers, Canon.

Cuando se publican las Letters from an English traveller in Spain, in 1778, on the origin and progress of poetry in that kingdom (1781) de John Talbot Dillon, el género de las historias de las literaturas nacionales acababa de nacer. Si bien este no adquiere su configuración típica hasta el siglo XIX, en el XVIII, y al amparo de un sistema ideológico y epistemológico ilustrado, aparecen las primeras obras que aglutinan y ordenan cronológicamente los logros literarios de cada nación. De aquí la importancia que desde los primeros trabajos canónicos sobre los inicios historiográficos 
se le ha concedido al marcho dieciochesco (Díaz-Plaja, 1949; Baasner, 1995; Cebrián, 1996) y que sigue dándosele en la actualidad (Urzainqui, Álvarez Barrientos, Aguilar Piñal o Checa Beltrán). ${ }^{1}$

Para comprender el surgimiento de estas obras y el porqué de presentar la materia literaria en una narración histórica debemos atender en primer lugar a la vocación historiadora del siglo XVIII, como consecuencia de ese afán enciclopédico con que se persigue un saber universal (Maravall, 1972). En estos textos la historia literaria se concibe normalmente como una parte más de la historiografía general dieciochesca, y en concreto de la historia de la cultura, de donde aprehende los métodos y a cuyas motivaciones responde. ${ }^{2}$ El mismo historicismo se refleja en una clara voluntad por rescatar textos antiguos y conocer sus soportes, tanto que en ocasiones la labor del historiador acaba resultando un catálogo de autores y obras.

En estos primeros ensayos el objeto de estudio, la literatura, se aborda en relación con otro concepto nuevo: el de nación. En efecto, el siglo XVIII es de suma importancia en la construcción de la identidad española (Aguilar Piñal, 2016: 411 y ss.) y en el último tercio de siglo se puede hablar ya como mínimo de una «identidad prenacional» (Pérez Isasi, 2006: 530). Con la constancia de la diferencia entre las distintas naciones de Europa, los ilustrados de los distintos estados europeos entienden que deben defender el legado histórico y cultural de su país y su posición en una particular carrera del saber. ${ }^{3}$ Esto justifica que también las historias de la cultura y de la literatura se conciban en los límites de lo nacional, lo cual plantea sin duda una serie de problemas metodológicos, ya que para hablar de su literatura se debe definir antes lo español. ${ }^{4}$ En tal sentido, hay quien opta por tratar en exclusiva la literatura «castellana», ${ }^{5}$ lo que resuelve en parte el problema. Sin embargo, al considerar la literatura española no era raro incluir la portuguesa, aunque sí lo era algo más incluir la literatura hispanoamericana. Otra disyuntiva se planteaba en el eje temporal: lo español podía abarcar desde los hispanorromanos hasta la actualidad, o comenzar con la aparición de las lenguas romances en la Edad Media.

Por otro lado, junto con el recorrido histórico y el concepto de nación, literatura es el tercer vértice del sintagma que nos interesa (el de las «historias de las literaturas nacionales»). Como ha sido bien estudiado, la voz literatura designaba el XVIII todo el saber escrito, tanto las ciencias como las «buenas letras»o «letras humanas» (algo más o menos equivalente a nuestra idea de humanidades). Para el concepto de lo literario se empleaba entonces el término «poesía», donde se reúnen todos los géneros que tiene en cuenta la preceptiva clásica, mientras que «elocuencia» comprende los escritos en prosa con un reconocible carácter estético. La suma de ambas se reúne en la categoría de «bellas letras», quizá la expresión más cercana a nuestro concepto de literatura, y que a

\footnotetext{
${ }^{1}$ No hace falta recordar los precedentes en los trabajos bibliográficos de Nicolás Antonio: Bibliotheca hispana nova (1672) y Bibliotheca hispana vetus (1696).

2 «Esta consideración de la historia de la literatura como parte de la historia de la cultura, general en todo el siglo, es de suma importancia para el tema que nos ocupa porque ella es la que le va a suministrar su andamiaje cognoscitivo y sus planteamientos metodológicos básicos. De manera que los presupuestos teóricos de la historia cultural son los que en términos generales sirven también para los de la historia literaria» (Urzainqui, 2004: 215-216).

3 «Este sentimiento patriótico se forjó también por enfrentamiento, pues durante el siglo XVIII España sufrió una serie de acosos, tanto bélicos (que le hacen perder importantes zonas de su imperio), como propagandísticos (leyenda negra, Inquisición, conquista de América, banalidad de la cultura nacional), que obligaron a los gobernantes a trazar un programa para contrarrestar esos ataques» (Álvarez Barrientos, 2004: 102).

${ }_{5}^{4}$ Problemas que tampoco están resueltos a principios del XIX: Pérez Isasi, 2013.

${ }^{5}$ Velázquez, Tomás Antonio Sánchez, Conti y otros más, como veremos.
} 
su vez entraba dentro del más amplio concepto de «bellas artes». ${ }^{6}$ Es en la Geschichte der Spanischen Poesie und Beredsamkeit de Bouterwek (1804, trad. de 1829) donde vemos por primera vez el término «literatura» empleado en el sentido actual. Antes de esta traslación semántica, los autores toman generalmente dos caminos: acotar su objeto de estudio haciendo historias de la poesía, o tratar de forma más amplia la cultura nacional con historias de la literatura. Las primeras destacan por tratar de forma pionera la materia literaria en sí misma, las segundas lo hacen solo como un capítulo más dentro del saber que ha producido la nación.

Al primer tipo pertenecen las Memorias para la historia de la poesía y poetas españoles del padre Martín Sarmiento, escritas en 1745, pero publicadas en 1775. Este esfuerzo por recopilar autores, obras y fuentes textuales, por encargo del cardenal italiano Valenti Gonzaga, quizá merezca ser considerado como el primer paso de la historiografía literaria española del siglo XVIII, aunque la carencia de una ordenación narrativa de la información hace que no la podamos calificar como una historia literaria propiamente dicha. No ocurre ya así con los Orígenes de la poesía castellana (1754) de Luis José de Velázquez, considerada ampliamente como la primera historia de la literatura española. ${ }^{7}$ Es él quien consolida la expresión «Siglo de Oro» para la poesía del siglo XVI y propone una periodización de la tradición española en cuatro edades que se corresponden con el ciclo vital de un organismo: infancia, juventud, madurez y vejez, como ya había hecho Aristóteles para la tragedia, y como luego había adaptado Vasari en el Renacimiento (Urzainqui, 2007: 654). Es una obra de marcado criterio neoclásico, como lo demuestra el que considere una época de vejez y decadencia el Barroco español, un «depravado gusto» del que culpa a la influencia italiana de «Marini». ${ }^{8}$

El caso de Velázquez fue excepcional y llama la atención frente a las más habituales historias de la literatura, como la que se propusieron los hermanos Pedro y Rafael Rodríguez Mohedano con su Historia literaria de España desde su primera población hasta nuestros días (1766-1791), cuya «desaforada erudición, poblada de conjeturas y digresiones de todo tipo, hará que la obra se trunque en el siglo I de nuestra era con la obra de Lucano» (Urzainqui, 2007: 660). No obstante, pudieron incluir ciertas apreciaciones sobre la literatura española moderna, y sus reflexiones teóricas sobre cómo se construye una historia de la cultura nacional merecen ser notadas. También se lo propuso — con más éxito y notable difusión a través de numerosas traducciones- el jesuita exiliado Juan Andrés en su titánico Dell'origine, progressi e stato attuale d'ogni letteratura (1782-1799), traducido al español enseguida por su hermano: Origen, progresos y estado actual de toda la literatura (1784-1806). Aquí no solo se revisa la cultura nacional, sino que más bien se presenta como una historia de la cultura universal, concibiendo dos grandes apartados que la dividen entre «Buenas Letras» y «Ciencias». La amplitud de su campo de estudio ha hecho que se hable de Juan Andrés como un pionero de los estudios de literatura comparada (Aullón de Haro, 2002). Y también en esta línea se sitúa un compañero de orden y exilio, Francisco Masdeu, con su Storia critica della cultura spagnuola (1781-1787), traducida poco después al español en 1783-1805.

Sin embargo, la reflexión sobre la tradición literaria española en el siglo XVIII no se reduce a estos títulos. En realidad, ya en la Poética de Luzán (1737) y en otros

\footnotetext{
${ }^{6}$ Vid. Inke Gunia, 2008: 89-135.

${ }^{7}$ De hecho estos Orígenes de Velázquez son la fecha de partida del repertorio bibliográfico de Fermín de los Reyes Gómez (2010). Vid. también Philip Deacon, 1978.

${ }^{8}$ Giambattista Marino (1569-1625), a quien también culpará Dillon.
} 
textos teóricos, ${ }^{9}$ se trata tangencialmente de cuestiones históricas, igual que ocurre en otros que se ocupan de la historia de la lengua, como los Orígenes de la lengua española (1737) de Mayans. También son relevantes las colecciones, ediciones y antologías de autores españoles de la Edad Media y Siglos de Oro que aparecen en la segunda mitad de siglo y que, además de hacer observaciones críticas en sus introducciones y comentarios, abonan el campo de la historiografía literaria posterior al divulgar textos a veces desconocidos. Así, Tomás Antonio Sánchez rescata el Poema del Cid en su Colección de poesías castellanas anteriores al siglo XV (1779-1790), dando una nueva dimensión a la literatura medieval española. Giovan Battista Conti en cierto modo continuó esta empresa con su bilingüe Colección de poesías castellanas traducidas en verso toscano (1782-1790), incluyendo autores del siglo XV y XVI, y anterior es el Parnaso español de López de Sedano (1768-1778), antología de la que Masdeu toma algunos poemas para traducirlos al italiano junto con otros más en sus Poesie di ventidue autori spagnuoli del Cinquecento (1786). Una mención aparte merece la obra de otro jesuita exiliado en Italia, Francisco Javier Lampillas. Su Saggio storico-apologetico della letteratura spagnuola contro le pregiudicate opinioni di alcuni moderni scrittori italiani (1778-1781) ${ }^{10}$ no es tampoco una historia literaria, sino, como su título indica, un trabajo apologético con el que pretende defender la cultura y letras españolas frente a los ataques de críticos italianos. No obstante, su repaso de la historia literaria española es muy completo, y su contribución a la historiografía literaria decisiva.

Manuel José Quintana y su antología de Poesías escogidas (1796) ya marcan un cambio de tendencia en los trabajos sobre historia literaria española al hacerse eco de la importancia del romancero (Navas Ruiz, 2002: 299). Pero es la historia de Bouterwek (1804) la que dota de un modelo sólido a la historiografía literaria española, junto con la posterior de Sismondi (1813), traduciéndose aquel al español en 1829. Años después, el Manual de Literatura de Gil de Zárate (1842-1844) confirma que la materia históricoliteraria se ha hecho ya un hueco en los planes de estudio del XIX, aunque «no se publica obra de fundamento sólido hasta que el año 1861 José Amador de los Ríos inició la edición de su Historia crítica de la literatura española» (Romero Tobar, 2010: 472).

\section{LA LITERATURA ESPAÑOLA BAJO LA MIRADA EXTERIOR: SIGLO XVIII}

Como hemos visto con Juan Andrés y el resto de jesuitas exiliados, en la elaboración de estas primeras aproximaciones historiográficas influye la visión extranjera de la literatura española. También en la segunda mitad del XVIII, y especialmente en las últimas tres décadas, la diversa recepción que franceses, italianos, ingleses y alemanes hacen de la tradición literaria española entra en diálogo con los autores nacionales, dando lugar a un debate en torno a su valor que presentó innumerables y complejas aristas. Este debate se enmarca además en otro mayor sobre el legado cultural español en la Europa moderna, que principalmente los franceses habían puesto en duda, y que conectaba con la pervivencia ilustrada de la leyenda negra. Sin embargo es también en las últimas décadas del XVIII cuando esta visión empieza a

\footnotetext{
${ }^{9}$ Pensamos, por ejemplo, en las versiones españolas de Batteaux (García de Arrieta, Principios filosóficos de literatura, 1797-1805) y Blair (Munárriz, Lecciones de poética y retórica, 1798-1801), ya a finales de siglo.

${ }^{10}$ Traducción al español de Josefa Amar y Borbón (1782-1786), Ensayo histórico apologético de la literatura española contra las opiniones preocupadas de algunos escritores modernos italianos, Zaragoza, Oficina de Blas Miedes.
} 
cambiar, con la ayuda de ingleses y alemanes, hacia una más simpática pero no menos contaminada de tópicos. Hablamos de la España orientalizada de los románticos, visión que tras Wilhelm von Humboldt reprodujeron en el XIX Lord Byron, Washington Irving, Victor Hugo o Théophile Gautier. ${ }^{11}$

En torno a la pertinencia del término leyenda negra y lo que significa, los historiadores no se han puesto aún de acuerdo, ${ }^{12}$ pero en cualquier caso, es sumamente conocido que durante la hegemonía política del imperio español en los siglos XVI y XVII se construyó un relato propagandístico según el cual los españoles eran bárbaros, crueles y avariciosos, basándose en historias, muchas veces exageradas, sobre la conquista de América y los castigos de la temida Inquisición española. El resto de potencias que disputaban esa hegemonía, como Francia y Reino Unido, tenían lógicamente un interés en divulgar ese discurso, que en buena medida se había originado en los Países Bajos ocupados por España, como ya señaló Pierre Chaunu (1976).

Sin embargo, desde la decaída del poder de los Austrias, y sobre todo comenzado ya el siglo XVIII, esa visión de lo español que repiten intelectuales de distintos países cambia ligeramente. Ya no se destacan tanto esos personajes que representan la violencia desmedida y hasta sadismo de los españoles -el conquistador, el inquisidor o el demonizado Felipe II-, sino que se habla de su atraso cultural respecto a Europa, identificado con la intolerancia religiosa y la cerrazón al progreso de las ciencias. ${ }^{13}$ Para los ilustrados europeos, España, ese vasto imperio inmóvil, es el símbolo de que las sociedades que no se ilustran están destinadas al fracaso político y económico. Se ha indicado comúnmente que en la creación y difusión de estas últimas ideas se encuentran con protagonismo los ilustrados franceses, y efectivamente son muy conocidas las apreciaciones de Voltaire y Montesquieu en torno al atraso cultural de España, la Inquisición, y también la literatura, ${ }^{14}$ aunque debemos entender que en buena medida se construyen como argumento político e ideológico contra sus detractores para justificar sus propios planteamientos ilustrados (Checa Beltrán, 2012). ${ }^{15}$ Quizá el ejemplo más extremo de esta visión es el conocido y feroz artículo «Espagne» (1782) de Masson de Morvilliers en la Encyclopédie méthodique, donde de alguna forma se sintetizan todos esos prejuicios negativos que circulaban en el siglo.

Estas visiones negativas expulsan a España a la periferia de Europa en términos de legado cultural e impiden su conocimiento objetivo. En relación con ello, tanto en Italia como en Francia se reproducen comentarios denigratorios sobre la literatura española y su «mal gusto», en buena medida identificado con su periodo barroco - esto es: su lenguaje poético más original y distintivo con respecto a la tradición petrarquista común a Europa-, originando una serie de polémicas al respecto. Los españoles se sintieron obviamente obligados a responder, y en torno a las tres últimas décadas del siglo se organiza un fértil debate europeo sobre la literatura española. Quizá la más

\footnotetext{
${ }^{11}$ Vid. Xavier Andreu Miralles, 2016.
}

${ }^{12}$ Así, para Pérez Magallón (2012: 13), el término se usa «de modo automático e indiscriminado para referirse a todo aquello que critica o censura a España», y Checa Beltrán (2012), en el mismo volumen, apunta la existencia de otra «leyenda rosa» sobre España en la Europa dieciochesca. Por otro lado, los trabajos que se reúnen en el más reciente La sombra de la leyenda negra (Villaverde Rico y Castilla Urbano, 2016) sí adoptan con comodidad el término.

${ }^{13}$ Pérez Magallón (2012), que rastrea ese prejuicio sobre la «ignorancia» de los españoles, indica que este no aparece antes del siglo XVIII, época en la que esa idea se incorpora al imaginario de lo español o leyenda negra.

${ }^{14}$ Es conocida la sentencia de Montesquieu sobre el Quijote: «Le seul de leurs livres qui soit bon est celui qui a fait voir le ridicule de tous les autres» (Montesquieu, 1831: 197).

${ }^{15}$ Para una revisión de estas ideas sobre Montesquieu y Voltaire, vid. Françoise Étienvre, 2012. 
conocida de estas polémicas es la que generaron algunos críticos italianos con sus opiniones al respecto de la tradición española: principalmente Tiraboschi en su Storia della letteratura italiana (1772-1782) y Berttinelli con Del risorgimento d'Italia negli studi, nelle arti e nei costumi dopo il mille (1775), a quienes respondieron los jesuitas españoles exiliados Masdeu, Lampillas y Juan Andrés con las obras que hemos comentado antes, este último con un tono más comedido que sus apologistas compañeros (Comellas, 2017). A su vez, el artículo de Masson de Morvilliers, además de las protestas diplomáticas correspondientes, suscitó una serie de textos en defensa de España y su literatura. ${ }^{16}$ En la década siguiente el debate afecta a los propios españoles, que se dividen entre «apologistas» y «reformistas» (Checa, 2004: 148), adoptando una actitud más crítica estos segundos, que beben de opiniones asentadas entre los intelectuales europeos. ${ }^{17}$ Por tanto el debate sirvió para que los propios críticos y autores nacionales reflexionasen acerca de la historia literaria de España, lo que tuvo como consecuencia que el siglo XIX planteara otras discusiones sobre el carácter romántico o clásico de su literatura: discusiones que tienen como protagonistas a Böhl de Faber y José Joaquín de Mora a partir de 1814 en lo que se ha llamado la querella calderoniana.

El repaso que acabamos de hacer permite observar que este periodo actuó como reactivo para generar una conciencia identitaria de la literatura española que serviría de punto de partida para la nueva conciencia diferencial que se terminó de gestar en el siglo XIX. Pero además sirvió para difundir los logros culturales y literarios fuera de España. Así, en Italia, junto con los trabajos de Lampillas (1778-1781), Masdeu (17811787) o Juan Andrés (1782-1799), entre otros, el italiano Conti ${ }^{18}$ se encargó de divulgar textos fundamentales de la literatura áurea española en su bien acogida Colección bilingüe (1782), que además contará con una reedición italiana de 1818 titulada Scelta di poesie castigliane del secolo XVI tradote al verso toscano. La Colección tuvo también buena acogida francesa, como demuestra el décimo tomo del Esprit des journaux, François et étrangers (1790: 190): «Le choix qu'a fait M. Conti des plus belles fleurs du parnasse espagnol, ne pouvoit être plus judicieux ni mieux exposé».

Por otro lado, en estas últimas décadas se abren en Francia canales de comunicación más objetivos para difundir la cultura española, entre ellos el que establece Bricaire de la Dixmerie en su revista $L$ 'Éspagne littéraire (1774). ${ }^{19}$ Sin embargo, hasta la primera década del XIX la literatura española en el país vecino es «en général peu connue et mal jugée» (Essai: 1$),{ }^{20}$ y muestra de ello también son las escasas páginas que Madame de Staël le dedica en su gran obra de literaturas comparadas De la littérature considérée dans ses rapports avec les institutions sociales (1800), con más tópicos generales que observaciones histórico-críticas. Antes del Essai que acabamos de citar había salido el Itinéraire descriptif de l'Espagne (1808) de Laborde, pero es

\footnotetext{
${ }^{16}$ Respondió Cavanilles con sus Obvservations de M. l'Abbé Cavanilles sur l'article Espagne de la Nouvelle Encyclopédie (1784), en 1786 Carlo Denina con un discurso leído en la Academia de Ciencias de Berlín, y Juan Pablo Forner con su Oración apologética por la España y su mérito literario del mismo año (Comellas, 2017: 145).

${ }^{17}$ Vid. también Checa, 1994.

${ }^{18}$ Para más información sobre Conti y su Colección, vid. D’Agostino, 2014. Y para la difusión en general de la cultura española en Italia, Maurizio Fabbri, 2012.

${ }_{19}$ «as buenas relaciones entre los tres periódicos citados (Journal étranger, L'année littéraire y L'Espagne littéraire) permiten hablar de una "red" periodística francesa interesada en dar a conocer en Francia la cultura española: sus respectivos editores se conocen, se aprecian y comparten su estima por el legado cultural español» (Checa, 2012: 123).

${ }^{20}$ A lo largo del artículo citaré las dos obras por el título, y no por su autor, para mayor comodidad del lector: Letters y Essai.
} 
después de aquel cuando se divulgan las historias de la literatura española en Francia, y con ello un verdadero conocimiento del legado literario español: en 1812 ve la luz la traducción francesa de Bouterwek, en 1813 se publica De la littérature du midi de l'Europe de Sismondi, y en 1814 las opiniones del teatro español de Schlegel traducidas al francés por Necker de Saussure. ${ }^{21}$ En definitiva, debemos esperar al siglo XIX para que los conocimientos sobre historia literaria española se instalen en Francia e Italia.

Distinto parece ser el caso en Alemania y Reino Unido, que miran con menos altivez y más curiosidad la literatura española, y que ya en la década de los setenta han iniciado su estudio. De sobra es conocida la relevancia del hispanismo alemán y su labor en la revalorización de la cultura española, sobre todo a través del Romanticismo. ${ }^{22}$ En este sentido, son de vital importancia las ideas de Herder sobre el Volksgeist que ejemplifica con la literatura española y su romancero, y que cristalizan más tarde en Schlegel, para ser introducidas por Böhl de Faber en nuestro país. Sin embargo, hay precedentes anteriores: ya a finales del siglo XVIII Göttingen, y luego Leipzig son importantes centros universitarios de difusión de la literatura española en Europa. Johann Andreas Dieze (1729-1785) ${ }^{23}$ fue encargado de la biblioteca de la Universidad de Göttingen, y al menos hasta él se puede remontar el hispanismo alemán. ${ }^{24}$ Fue traductor de Mayans y también de los Orígenes de Velázquez, cuya versión (Geschichte der Spanischen Dichtkunst; aus dem Spanischen übersetzt und mit Anmerkungen erläutert, Göttingen, 1769) se enriquecería con gran cantidad de comentarios propios que construyen un texto paralelo al del español. Su temprana fecha de publicación hace de este doble texto (Velázquez-Dieze) un caso único de estudio sobre la literatura española fuera de España, además de texto clave y punto de referencia para los autores alemanes que quisieron conocer nuestra tradición literaria, como fue Herder. En el seno de la misma Universidad de Göttingen, donde además se formó el joven Ticknor, ${ }^{25}$ también se produjo la obra de Bouterwek, que en realidad fue parte de un proyecto mayor concebido por Gottfried Eichorn y que abarcaría todas las literaturas nacionales europeas, siendo el cuarto tomo (1804) el dedicado a la española y portuguesa. También se deben mencionar los viajeros alemanes del XVIII (FriedrichStegmann 2014), entre los cuales destacó sin duda Wilhelm Von Humboldt y su Diario de viaje por España (1799-1800) — según su autor incitado por Goethe- y que convierte la Península en destino de interés para las celebridades alemanas. ${ }^{26}$

\section{LOS VIAJEROS INGLESES EN LA DIFUSIÓN EUROPEA DE LA LITERATURA ESPAÑOLA}

También los ingleses cuentan con precedentes que se remontan a la década de los setenta. En su caso fueron principalmente los viajeros quienes en gran medida asumieron la iniciativa de interesarse por España y su literatura, produciendo una serie

${ }^{21}$ Necker de Saussure (1814), Cours de littérature dramatique, Paris, Paschoud.

22 «[L]a determinación del "espíritu nacional" en la literatura española está marcada fundamentalmente por el primer hispanismo universitario de Alemania en el paso del XVIII al XIX» (Romero Tobar, 2010: 466). Además, véanse los trabajos de Bertrand (1922), Krömer (1984), Briesemeister (1984), Schrader (1991) o Strosetzski (2002), entre otros.

${ }^{23}$ Vid. Bertrand, 1922.

24 Poco antes Lessing había reconocido la figura de Lope de Vega en su Hamburgische Dramaturgie (1767).

${ }^{25}$ Autor de la primera historia de la literatura española decimonónica proveniente del ámbito anglosajón: History of Spanish literature (1849).

26 Aunque son varios los nombres de viajeros alemanes que llegan a España anteriormente, «hasta finales de los años noventa del siglo XVIII, cuando vinieron los hermanos Humboldt, España no era uno de los destinos de las celebridades alemanas. Sus países de moda fueron durante todo ese siglo sobre todo Francia, Suiza, Inglaterra y, por supuesto, Italia» (Friedrich-Stegmann, 2014: 39). 
de libros de viajes en los que podemos encontrar las bases del primer hispanismo inglés. Estos escritos viajeros se habían hecho populares en una sociedad familiarizada con el Grand Tour, con el que desde el siglo XVII los jóvenes de alta clase ingleses se formaban y conocían las maravillas de Europa y su historia. ${ }^{27}$ En el XVIII muchos de estos viajeros dejan testimonios (epistolares o a modo de diario) de sus experiencias que pronto se convierten en una moda con éxito en el mercado editorial: «By the end of the century, non-fictional travel accounts were the second best-selling genre in England after the novel» (Marino, 2014: 187). ${ }^{28}$

Sin embargo, España no se encontraba en el recorrido habitual de este Grand Tour - donde sí estaban Francia e Italia-, debido en parte a una antigua enemistad política, pero también a un acceso más difícil a la Península. Es en los setenta y ochenta cuando un número significativo de viajeros ingleses pasan por España y publican sus experiencias, renovando un género que había gastado los habituales destinos. ${ }^{29}$ Estos viajeros eran «a motley group composed of political exiles, diplomats, military officers, Anglican Priests, Roman-Catholics semi-expatriated, businessmen, writers, and men of leisure and means», cuyos intereses iban desde «mere expectations of a pleasurable experience to serious attempts at understanding Spanish society and culture» (Bacigalupo, 1978: 118).

Además, estos libros de viajeros ingleses, entre los que podemos mencionar los de Richard Twiss, William Dalrymple o Henry Swinburne, ${ }^{30}$ tuvieron una difusión que sobrepasó las fronteras británicas y llegó a distintos países de Europa, debido en buena medida a las traducciones alemanas con las que contaron: es el caso de Baretti, George Glas (Leipzig, 1777 y 1789), Richard Twiss (Leipzig, 1777), Joseph Towsend (Leipzig, 1792) o el propio Dillon (Leipzig, 1782). De la traducción alemana del Journey de Baretti en 1772 se sabe además que fue conocida por Herder, e influyó de forma decisiva en su interés hacia la literatura española (Friedrich-Stegmann, 2014: 47).

En cuanto a la visión que trazan de España, no puede negarse que presentan la Península con un exotismo que adelanta algunos aspectos de la visión romántica. Así Edward Clarke (1763) se muestra sorprendido por la valentía de hombres y caballos en las corridas de toros; también la visión de la mujer y la sensualidad (Bolufer, 2003) entran en ese imaginario previsible. Viajar por pésimas carreteras (incluso Dillon debe admitirlo) o dormir con chinches puede ser interpretado como el precio inevitable que tiene alejarse de la civilización y encontrar aventura - también es habitual el hidalgo como símbolo de una nobleza inmóvil que no entiende el nuevo mundo comercial-, pero la mayor de las críticas y la más general es la censura de la Inquisición, en algunos

27 Aunque, como indica Bolufer (2003), ese Grand Tour con el que los jóvenes ingleses se formaban y que casi suponía un ritual social, «hoy sabemos que esa fue solo la manifestación más selecta y elitista de una experiencia, la del viaje, mucho más variada en sus formas, sus motivaciones y sus protagonistas». Véase Mary Louise Pratt, 1992, y Katherine Turner, 2001.

${ }^{28}$ Para tal afirmación se basa en los estudios de Batten, 1978.

29 Entre sus comentaristas pueden recordarse Ian Robertson (1976), Mario Ford Bacigalupo (1978) y Ana Clara Guerrero (1990). También la misma Bolufer (2003) estudia la imagen de España que reproducen estos viajeros y Ortas Durand (2006) ha estudiado su recepción de Cervantes.

${ }^{30}$ En una lista representativa entrarían Edward Clarke (Letters concerning the Spanish nation: written at Madrid during the years 1760 and 1761, 1763), Giuseppe Baretti (Journey from London to Genoa through England, Portugal, Spain and France, 1770), Richard Twiss (Travels Through Portugal and Spain in 1772 and 1773, 1775), Joseph Marshall (Travels through France and Spain, in the years 1770 and 1771, 1776), William Dalrymple (Travels through Spain and Portugal in 1774, 1777), Philip Thicknesse (A year's journey through France and part of Spain, 1777), Henry Swinburne (Travels through Spain in the Years 1775 and 1776, 1779), Alexander Jardine (Letters from Barbary, France, Spain, Portugal, 1788), Joseph Townsend (A journey through Spain in the years 1786 and 1787, 1792), y el propio Dillon. 
casos atacando «el absurdo poder de la religión» (Dalrymple, 1977). Con todo, la imagen que se ofrece es siempre más amable que la de Aulnoy, y como Hönsch (2000) ha señalado, supondrían una superación de los modelos franceses y un anticipo de los alemanes en la evolución de la imagen de España.

Algunos de estos viajeros repararán además en la literatura española, para la que tienen mejores palabras que los franceses, algo que ellos mismos se encargan de señalar. Así Richard Twiss (1775) defiende la Araucana de Ercilla contra los juicios negativos de Voltaire, y en el prefacio de las Letters de Dillon se achaca al «prejuicio nacional» la opinión negativa de Montesquieu sobre la literatura española: «It has been said by a great and learned French writer that the Spaniards have but one book, and that one shews the ridicule of all the others. How far such a general reflection appears strained and tinctured with national prejudice, I shall leave to others to consider» (Letters: V). En este mismo tono, Giuseppe Baretti, italiano residente en Londres, en su Discours sur Shakespeare et sur Monsieur de Voltaire (1772) ya había rechazado la rigidez del neoclasicismo de Voltaire y defendido la «experiencia» de Shakespeare y Lope de Vega (Baretti, 1972, II: 548). Quizá fruto de una mayor rivalidad política, los desacuerdos en el terreno estético entre ingleses y franceses parecen favorecer a que aquellos se interesen e incluso defiendan la singularidad del gusto español.

Entre los viajeros, las opiniones sobre materia literaria se remontan al menos a Edward Clarke (1763), quien a pesar de no ser un gran conocedor de nuestra tradición, hace una extraña lista de autores españoles, de la que el más reconocido es Ercilla y $L a$ Araucana, poema que compara con Homero. También es conocida y admirada la comedia del Siglo de Oro, y las comparaciones de Lope y Calderón con Shakespeare se hacen habituales. ${ }^{31}$ Por eso no extraña que para George Glass, en su A description of the Canary Islands (1764: 302), el drama español esté por encima de cualquier otra nación de Europa, y Baretti alabe la originalidad de Lope, que luego el poeta William Hayley también estudiará (Comellas y Sánchez Jiménez, 2018).

Sin embargo, ninguno de ellos contribuyó tanto a la difusión de la literatura española como John Talbot Dillon en sus Letters from an English traveller in Spain, in 1778 , on the origin and progress of poetry in that kingdom (1781), añadiendo al género de viajes un tema que no se había abordado antes de forma directa, y haciéndolo a través de un relato histórico que le merece el título de historia de la literatura. Como se indica en el prefacio, «the mountain of Parnassus has not been visited by the curious traveller, and the Spanish muse has tuned her lyre without being disturbed by the unhallowed step of the rambling stranger» (Letters: III-IV). Con las Letters, Dillon viene a enriquecer el género de viajes a España con una materia a la que se había dado escasa importancia, pero también produce una síntesis de la historia literaria española que apenas cuenta con precedentes en el extranjero, y que contribuyó de forma decisiva a la difusión de estos conocimientos en la Europa del setecientos.

JoHn TALbot DiLlon: LETTERS FROM AN ENGLISH TRAVELLER IN SPAIN, IN 1778, ON THE ORIGIN AND PROGRESS OF POETRY IN THAT KINGDOM $(1781)^{32}$

En este contexto deben analizarse las aportaciones que Sir John Talbot Dillon (1734-1806) hizo a la difusión de la historia literaria española en Europa. Fue hijo del irlandés Francis Dillon, barón del Sacro Imperio Romano Germánico, y de Mary, hija de Sir Mervyn Wingfield, sexto y último barón de Letheringham. A pesar de su

\footnotetext{
${ }^{31}$ Vid. Ángel-Luis Pujante, 2001.

${ }^{32}$ En este apartado las Letters de Dillon aparecen citadas solo por el número de página para facilitar la lectura.
} 
ascendencia irlandesa y su condición de católico, vivió la mayor parte de su vida en Inglaterra y se identificó como Englishman. A temprana edad entró en el Colegio de Westminster, donde recibió su primera educación. Allí permaneció hasta 1747, cuando entró en la Armada Real. Sin embargo, una desavenencia con sus superiores le hizo abandonarla apenas dos años más tarde. A partir de aquí comienzan una serie de viajes que llevan a Dillon por España, Bélgica, Austria y Francia, donde al parecer tenía amistades y parientes. Vivió una larga temporada en España y probablemente en ese tiempo aprendió la lengua con el dominio que le reconocieron sus contemporáneos, ${ }^{33}$ y que le hizo destacar entre sus compatriotas en el campo de los estudios hispánicos. Posiblemente viajó de nuevo a la península a finales de los sesenta o principios de los setenta, para volver una vez más en 1778. De esta última visita es de la que dejó rastro como escritor de libros de viajes, según vemos ahora.

Tras estas experiencias como viajero, que le reportaron un amplio conocimiento de varias lenguas, ${ }^{34}$ Dillon produjo una serie de obras en las que dejó ver su especial interés, entre otros temas, por la historia y la literatura españolas. En 1781 aparecieron sus Travels through Spain, with a view to illustrate the natural history and physical geography of that kingdom, in a series of letters. Como advierte en el prefacio, en la base de su texto está la obra de William Bowles An Introduction of the Natural History and Physical Geography of Spain (1775), a la que dio una estructura a su juicio más ordenada, añadiendo comentarios propios y sirviéndose del Viage de España (1775) de Antonio Ponz para ofrecer al público inglés una imagen del país mejor cuidada y más actualizada que la de su colega. ${ }^{35}$ Poco después volvió a aplicar sus conocimientos de la lengua española al traducir al inglés las reflexiones teóricas de Antonio Rafael Mengs en Sketches on the Art of Painting (1782), y un año después publicó A Political Survey of the Roman Empire. Más tarde llegan dos obras que se añaden a la producción hispanista de Dillon: The History of the Reign of Peter the Cruel, King of Castile and Leon (1788), que cuenta con una traducción francesa de 1790, y Alphonso and Eleonora, or, The Triumphs of Valour and Virtue (1800), dos ensayos históricos sobre Pedro el Cruel y Alfonso VIII respectivamente, en los que Dillon quiere limpiar la imagen de ambos monarcas (en el caso de Alphonse and Eleonora con un tratamiento más novelesco, quizá buscando atraer a un mayor público).

La única obra en la que Dillon trató directamente la historia literaria española fueron las Letters from an English traveller in Spain, in 1778, on the origin and progress of poetry in that kingdom, publicadas en Londres en 1781. Se trata de unas cartas dirigidas a un supuesto amigo al que dejó en Italia, en las que le comenta su viaje a España mientras le va exponiendo, en un ordenado relato histórico, el «origen y progreso» de su literatura. Estamos por tanto ante un libro de viajes, pero que por primera vez tiene por objeto la tradición literaria española en su conjunto, y de forma exclusiva. Los comentarios sobre el carácter de los españoles o sobre los avatares de su

${ }^{33}$ Giuseppe Baretti da cuenta de ello cuando critica la edición del Quijote de John Bowle (1781) por sus pobres conocimientos del español. El italiano le recomienda consultar a su amigo Dillon, al que le reconoce amplios conocimientos de la obra de Cervantes, además del dominio del idioma: «he speaks Spanish fluently» (Baretti, 1786: 231).

${ }^{34}$ En una carta en la que se refiere a su encuentro con Dillon, Mayans se asombra de su erudición, reconociendo sus habilidades para el alemán, italiano, francés y portugués, además del español (en Marino, 2014: 190).

35 «The resulting work offered one of the most complete pictures of Spain then available to the British reading public and it was favourably reviewed, although its focus on natural history and antiquity made it old-fashioned at a time when travelogues were increasingly concerned with politics and cultural anthropology» (Turner, 2004). 
viaje en realidad funcionan como un marco, y lo que de verdad interesa es ofrecer un sketch de nuestra historia literaria.

A la hora de tratar la literatura española, Dillon presenta una estructura basada en el itinerario de su viaje: Barcelona, Valencia, Madrid, Toledo, Madrid, el Escorial, Madrid, Burgos y Bilbao, de donde parte hacia el Reino Unido. Sus experiencias en uno u otro destino parecen motivar su explicación historiográfica, aunque podemos observar que los temas están previamente escogidos para contextualizar su objeto de estudio: la literatura española. Así, en la primera carta se describe la lengua castellana y en las siguientes (de la II a la VII) se tratan las literaturas romana y árabe para explicar el origen de la castellana, junto con otras literaturas ibéricas (provenzal y gallegoportuguesa). A continuación las cartas VIII-XII se centran en la literatura castellana, dividida en cuatro periodos. El resto de cartas deja de seguir cualquier orden histórico, y se suceden una sobre el teatro español, la biblioteca del Escorial, la vida de Lope de Vega, y también las distintas órdenes de nobleza en España o la poesía vasca.

La forma en que se ocupa de la tradición literaria española, con una narración cronológica que la divide en periodos, hace que las Letters sean merecedoras de ser consideradas como una historia de la literatura española (Bacigalupo, 1978: 132), y muy probablemente la primera escrita en inglés (Marino, 2014: 194). Para crear su historia literaria Dillon resuelve los problemas metodológicos de la historiografía literaria dieciochesca en cuanto a la delimitación de su objeto de estudio, planteando una historia de la poesía castellana, a la manera de Velázquez. De esta forma, el resto de literaturas ibéricas se tienen en cuenta por su influencia sobre la castellana, y la Hispania romana y la árabe se disponen como antecedentes del objeto de estudio.

También Dillon comparte el interés de los historiógrafos del XVIII en rescatar textos antiguos, y dedica muchos de sus comentarios a dejar constancia de las distintas ediciones, así como la localización de los manuscritos que nombra (por ejemplo el del Libro de Buen Amor). Además, su texto tiene el valor de proporcionar una información extremadamente actualizada, pues entre sus fuentes están, como él mismo señala, Velázquez (1754), López de Sedano (1768) y las Memorias de Sarmiento (1775), es decir, prácticamente los únicos trabajos de materia historiográfica literaria que habían compuesto autores españoles hasta la fecha, a espera de lo que los Lampillas, Juan Andrés, Sánchez o Masdeu darán a luz en las últimas dos décadas del siglo. A este material debemos añadir el que le proporcionó Mayans en su viaje, y otros hombres de letras también probablemente.

Por otro lado, la forma en que se presenta la historia literaria española — en un libro de viajes, y no como un tratado o ensayo científico-, ha hecho que las Letters no se encuentren entre los repertorios de historias de la literatura española. ${ }^{36}$ En efecto, Dillon aparece casi exclusivamente en estudios sobre viajeros ingleses en España (Bolufer, Guerrero, Ortas Durand, Robertson, Hönsch o Bacigalupo), y las aportaciones al estudio de su figura de hispanista han sido breves y superficiales en general. En ocasiones sí se ha tenido en cuenta a Dillon por su cervantismo: Ortas Durand (2006), en un libro en el que habla de otros viajeros ingleses que leyeron el Quijote; McDonald (1960) reconoce el papel puntero de Dillon en su difusión de la crítica sobre la novela; y Truman (2003) comenta su papel clave en la elaboración de la edición de Bowle, así como la opinión de Baretti de que Dillon y no Bowle debía hacer esa traducción. También recientemente se ha rescatado su figura de lopista (Comellas y Sánchez Jiménez, 2018), y se ha reconocido su aportación a la difusión del Libro de Buen Amor (Deyermond, 2004). Sin embargo, solo se han dedicado dos artículos exclusivamente a

\footnotetext{
${ }^{36}$ No aparece, efectivamente, en el completo y reciente repertorio de Fermín de los Reyes, 2010, ni en Baasner, 1995.
} 
las Letters: los de Otis Green (1973) y Nancy Marino (2014). El primero no va más allá de un resumen del contenido de cada carta, sin entrar en otros detalles. Por otro lado, el de Nancy Marino es quizá el trabajo más completo hasta la fecha sobre las Letters, y el único en que son tratadas en profundidad.

Entre las fuentes que Dillon utiliza destacan principalmente los Orígenes de Velázquez. De él toma una idéntica periodización de la literatura española y el concepto decisivo de decadencia sobre el que se construye su visión: tras llegar a su apogeo en el siglo XVI, la literatura española entra en una etapa de decadencia en el XVII, como es frecuente afirmar en la época. Sin embargo, esta idea evoluciona en Dillon para beneficio de los ingleses, que tomaron el relevo a los españoles en el trono de las letras: ${ }^{37}$

We may divide it [la poesía castellana] into four periods: the first from its early dawn till the reign of king John the $2^{\text {nd }}$; the next from this king to the days of Charles the $5^{\text {th }}$; the third from the emperor down to Philip the $4^{\text {th }}$; and the last from that reign down to Charles the $2^{\text {nd }}$, the last Austrian monarch, when the genius of Homer and Virgil seems to have fled from the banks of Manzanares, and to have fixed its residence on those of the Thames (107).

Por lo tanto la primera edad abarca la literatura medieval de los siglos XIII ${ }^{38} \mathrm{y}$ XIV, centrándose especialmente en la figura histórica de Alfonso X (también sus obras: Las siete partidas, Libro del Tesoro) y en el Libro de Buen Amor. ${ }^{39}$ Este último aún no contaba con su primera edición, que vendrá de la mano de Sánchez en el cuarto tomo (1790) de su Colección, mientras que Velázquez se había limitado a ofrecer un resumen, y admite no haber conocido el manuscrito. ${ }^{40}$ Dillon dice sí haberlo consultado en su visita a Toledo, dando cuenta de su estado («in a very imperfect condition, with many sheets tore out, and other unintelligible») y ofreciendo a continuación el mismo sumario que Velázquez (129).

A continuación se ocupa de la literatura del siglo $\mathrm{XV}$, en la que menciona a Álvaro de Luna, ${ }^{41}$ Juan de la Encina (Triunfo de la fama, Arte de poesía castellana y su producción dramática), o López de Ayala y sus traducciones. Se detiene más en la poesía de cancioneros, del que menciona el de Baena, y también en las Coplas de Mingo Revulgo, especulando sobre el autor de ellas (cree probable que fuera Fernán del

\footnotetext{
${ }^{37}$ Es interesante ver cómo Dillon es de los primeros en participar de un pensamiento común en la visión extranjera de la literatura española que se genera a finales del XVIII y que consolida el Romanticismo: el valor del legado literario español está en su pasado, y no en el presente, dominado por las aportaciones inglesas y francesas sobre todo.

${ }^{38}$ Del Cid habla más tarde, en la carta XVI. Interesa más la figura histórica y legendaria, aunque también menciona las crónicas de Alfonso X. Lo más probable es que no conociera aún el Poema, que en esos años comenzaba a divulgar Tomás Antonio Sánchez.

39 «A singular poet and satirist now occurs, who has escaped the researches of Don Nicolas Antonio, and most other biographers till discovered by Don Lewis Velazquez, knight of the order of St. James. This is Juan Ruiz, archi-priest of Hita, whose Works are in manuscript, in the library of Toledo, and who flourished in the year 1330» (129).

${ }^{40}$ «Parece que se llamaba Juan Ruiz, y que era Arcipreste de Hita, que en aquel tiempo se diría Fita. Yo no he visto este código, aunque está en Toledo al presente, por lo cual no puedo dar razón de lo que acaso contenga más que el de la Librería de la Iglesia, y contrayéndome solamente a lo que en este se halla, es en resumen lo siguiente» (Velázquez, 1754: 65).

${ }^{41}$ Más conocido por su papel político, también se dedicó a la literatura. Su Libro de las claras e virtuosas mujeres (1446) se posiciona en contra de la literatura misógina de la que participa el Corbacho (1538). Vid. Lola Pons, 2008.
} 
Pulgar, ${ }^{42}$ valiéndose del juicio del historiador Mariana $)^{43}$ y describiéndola como una sátira política que ataca «the vices of king Henry the fourth» (150), aunque parecen interesarle más el Marqués de Santillana, Juan de Mena y Jorge Manrique. Del Marqués de Santillana ya había repasado su biografía en una carta anterior sobre poesía trovadoresca provenzal, y con Mena, como es frecuente en Dillon, se pierde en ediciones y publicaciones de las obras. Sintetiza la importancia de estos tres escritores diciendo que

Juan de Mena introduced an elegance of expression, George Manrique and his nephew polished her style, and embellished it with more easy rhyme. The marquis of Santillana disembarrassed her from the setters of couplets, and made her acquainted with the versification of the Provenzals and Italians (154-155).

Como era de esperar, su carta más larga es la XI (43 páginas), dedicada a la literatura del siglo XVI, que Dillon llama recurrentemente «the golden age of poetry in Spain». Recuerda la influencia italiana en «the first promoters of this brilliant revolution in Spain», y que «a set of men was not wanting, who looked with jealous eye on the versification of the Italians» (158-160). A continuación comenta la figura de Boscán y su contacto con las medidas italianas a través de Navagero, pero se detiene más en Diego Hurtado de Mendoza, a quien dedica cuatro páginas en las que se muestra fascinado por su biografía, para luego atribuirle el Lazarillo: «a little piece [...] which was soon after translated into Italian and into English: the great autor little thought at that time, that his performance would ever serve to grace the stalls of Moorfields» (164). Como cabe suponer, también dedica las debidas páginas a Garcilaso, de quien opina que «has justly been filled The Prince of Spanish poets, having with his friend Boscán brought the Spanish poetry to its highest perfection» (168). Igual que ocurre en los Orígenes de Velázquez, la lista sigue con Luis de Haro, Gutierre de Cetina, Fernando de Herrera y Fray Luis de León, para luego hablar de Lope de Rueda y Juan de la Cueva. También como Velázquez, opina que algunos de los últimos poetas brillantes antes de la decadencia de las letras españolas fueron Vicente Espinel, Luis de Ulloa, Pedro de Espinosa, ${ }^{44}$ Juan de Jáuregui, Cristóbal de Mesa y Francisco de Quevedo. En este último, cuyos Sueños parecen ser conocidos y estimados por su interlocutor, sí se detiene bastante más que Velázquez y deja patente su admiración por él. Ensalza su «masculine spirit, or the keenness of his satire», su carácter irreverente y su profunda moralidad religiosa, junto con su gusto refinado (177-181).

La cuarta edad de la poesía española para Dillon está marcada por un «false taste», el «depravado gusto» en Velázquez, y como este, atribuye tal desafortunada evolución a un contagio del estilo de los italianos contemporáneos. La Agudeza y arte de ingenio de Gracián es el síntoma de esta «corrupción». De nuevo sigue a Velázquez al considerar que son tres grupos los culpables de ella. El primero es el de los corruptores del drama: Virués, Lope de Vega, Montalbán, Calderón, Salazar, ${ }^{45}$

${ }^{42}$ Fernán o Fernando del Pulgar, además de glosar las Coplas de Mingo Revulgo, escribió el Libro de los claros varones de Castilla (1486) y la Crónica de los Reyes Católicos (1565), atribuida erróneamente a Nebrija, su traductor.

43 «Llegó esto a tanto, que Hernando del Pulgar, hombre conocido en aquel tiempo, por su ingenio, y por lo que escribió, trovó unas coplas muy artificiosas, que se llaman de Mingo Revulgo, en que callado su nombre, por el peligro que le corriera...» (Mariana, 1719: 343).

44 Pedro de Espinosa (1578-1650), publicó en 1605 las Flores de poetas españoles, donde se incluyen poemas suyos y de otros autores, como Góngora, Quevedo o los Argensola.

${ }^{45}$ Agustín de Salazar (1636-1675). Sobre su producción dramática vid. O’Connor, 2004. 
Candamo y Zamora, ${ }^{46}$ que «violated all the laws of drama, and introduced innumerable defects on the stage, which have never been erradicated» (203). Esta opinión típicamente neoclásica está calcada de Velázquez (es una traducción en realidad, como ocurre en muchos otros pasajes), ${ }^{47}$ y esto explica que luego Dillon se contradiga y muestre su faceta de lopista en la carta XV, dedicada exclusivamente al Fénix (Comellas y Sánchez Jiménez, 2018), y coincida con su interlocutor y con la opinión general de otros viajeros ingleses en su admiración por «the fecundity of his genius» (243). El segundo y tercer grupo son respectivamente los conceptistas y culteranos, con Góngora a la cabeza de estos últimos, quien «contributed to diffuse an universal bad taste, and discredit the muses». Sin embargo, Dillon no insiste en las argumentaciones de Velázquez sobre ese mal gusto, y acaba aquí su capítulo de la literatura del XVII. Al considerar la literatura actual española, Dillon sí se distancia de Velázquez — que tiene en mente una especie de restauración del buen gusto - y dice que bajo el dominio de los Borbones y los «effeminate modes of Versailles», no solo la «Spanish gravity was put out of contenance», sino que hasta los mismos españoles han dejado de llevar sus preciados bigotes y perillas (205-206).

Sigue con la literatura española en la carta XIV, donde trata las «Revolutions and progress of the Spanish Drama». También en este apéndice el texto de Dillon coincide con Velázquez, y se puede comprobar con facilidad que se corresponde con los apartados que este dedica a la comedia y tragedia. Sin embargo, se hace patente el ojo inglés al mencionar las traducciones inglesas que conoce de la Celestina, y cuando llegamos a Lope de Vega, como también se había apuntado en el prefacio y luego en la carta XV, su genio se compara al de Shakespeare, con quien comparte «universal admiration» (243). También habla de Lope de Rueda, Virués, Calderón (en sintonía con Velázquez, no sale muy bien parado), y al hablar de la tragedia, ahora sí ve una influencia positiva del teatro francés en el español. Además, esta «poesía castellana» dividida en cuatro edades está precedida, del mismo modo que Velázquez, de cuatro literaturas que explican el «carácter» de aquella: los autores de la Hispania romana y visigótica, los autores árabes de Al-Ándalus, la poesía trovadoresca catalano-aragonesa y por último la gallego-portuguesa. Deja descolgada la literatura vasca hasta la carta XVIII, haciéndola coincidir con su parada en Vizcaya.

Según se deduce de lo dicho, la influencia de Velázquez es notable tanto en el contenido como en la estructura de las Letters. No obstante, las fuentes de Dillon van más allá, y como señala Marino (2014: 195),

Dillon quoted, consulted, or specifically mentioned in his study nearly fifty books: literary texts by Spanish, Portuguese, French, and English authors; collections of verse such as cancioneros and romanceros; histories of Spanish poetry; dictionaries and grammars of the Spanish, Portuguese, and Basque languages; histories of Spain; treatises on hidalguía; and church history. ${ }^{48}$

Incluye un aparato de referencias destinadas a explicar todo lo relativo a España - su lengua, su historia, sus costumbres_- para luego insertar ahí la información literaria, que en su mayoría corresponde a la lectura de Velázquez, y en menor medida a

${ }^{46}$ Antonio de Zamora (1665-1727). Vid. María Isabel González Roncero, 2011.

${ }^{47}$ En efecto, muchos pasajes son traducciones de Velázquez, seleccionados y ampliados con comentarios suyos: por ejemplo las pp. 40-43, que se corresponden sin muchos cambios con la «Poesía arábiga» en su fuente. No obstante, cuando se trata de una traducción literal más larga, sin ninguna participación suya, Dillon no lo oculta. Así, cuando se dispone a ofrecer el resumen de la Batalla de Don Carnal y Doña Cuaresma advierte que lo que sigue a continuación está «as given by Velázquez» (129).

${ }^{48}$ Véase el apéndice que ofrece al final de su artículo. 
López de Sedano y Sarmiento. ${ }^{49}$ Dillon usa a Aldrete y Mayans como referencia para su presentación de la lengua española, con la que inicia el volumen, y también se muestra conocedor del Tesoro de Covarrubias. En sus presentaciones históricas cita a Mariana y Zurita entre otros; y también conoce el Teatro crítico universal de Feijoo y las obras bibliográficas de Nicolás Antonio (Bibliotheca hispana, 1672-1696), Casiri (Biblioteca Arábico-Hispana, 1770) o Pellicer (Ensayo de una biblioteca de traductores españoles, 1778).

Quizá el aspecto más original de Dillon respecto a las fuentes que consulta es su cervantismo. Las referencias al Quijote son incontables, y van desde citas y recuerdos de sus pasajes preferidos, hasta la inclusión del lenguaje cervantino en el suyo propio. ${ }^{50}$ Así, evoca el lance final con el bachiller Sansón Carrasco cuando llega a Barcelona (14), interpreta la realidad de los españoles a través de la ficción de Cervantes (78 y 79), y hasta explica por qué en la edición de Peter Motteux (1733) no se deja entender bien el sentido de los «cuartos» de Rocinante (95). También muestra respeto por las opiniones literarias del narrador en el capítulo de la biblioteca de Don Quijote, que en ocasiones esgrime como autoridad crítica. Dillon, que se llama a sí mismo «quixotic traveller» (95), fue sin duda un inteligente y apasionado lector del Quijote, ${ }^{51}$ motivo por el que sus Letters destacan en el panorama historiográfico del momento. Como opina McDonald (1960: 34), el suyo fue «the travel book most notable for developing the motif of Quixote criticism in that genre before the Rambles [Inglis, 1840]».

Además, a lo largo del libro, Dillon da la impresión de ser un gran lector en varias lenguas: principalmente inglés, español y francés, aunque también conoce la tradición italiana. Entre los poetas que cita o alaba con recurrencia se encuentran Swift, John Milton (a quien compara con Ercilla y La Araucana), Shakespeare (comparado con Lope de Vega), Quevedo o Petrarca. También deja ver su lado bibliófilo en la carta III al hablar de una visita a la biblioteca de Mayans, a quien tuvo la oportunidad de conocer. La otra biblioteca presente, además de la de Don Quijote, es la del Escorial, que se trata en la carta XIII. Es una carta sobre todo dedicada a los traductores españoles, donde quizá se apoya también en la cuarta parte de los Orígenes.

Pero su curiosidad abarca otros terrenos muy diversos. Entre ellos destaca el histórico y el político. Dillon, que más adelante dedicará sendos libros a la historia de dos monarcas españoles, aquí se detiene en las biografías de los autores que le resultan más interesantes (Macías, Alfonso X, el Marqués de Villena o Lope de Vega), y parece atraerle la historia de España en general, en particular las relaciones que ha tenido con Inglaterra: la carta VI está dedicada a la batalla de Almansa (1707), en la que españoles y franceses derrotaron a los ingleses, después de que los portugueses los abandonaran en el campo de batalla. Por otro lado, también se aprecia en Dillon un hombre que está al tanto de la situación política que vivía, y hace continuamente alusiones más o menos explícitas a las tensiones de británicos con franceses, que entonces apoyaban la independencia de los EEUU, llegando a sugerir que pasó miedo en su viaje de Italia a España por si lo atacaban barcos franceses.

Como es de esperar, también acompaña su sketch de la literatura española con reflexiones sobre el carácter de los españoles, sus costumbres, instituciones, y sobre

${ }^{49}$ Algunos de los poemas que traduce Dillon parecen haber sido sacados del Parnaso (1768) de Sedano, y en varias ocasiones $(12,49,126,267)$ cita las opiniones de Sarmiento (1775), con las que a menudo coincide. También habría leído los prefacios de ambas obras.

50 «I now lay down my Spanish lance, as well as the golden helmet of Mambrino, and am hastening home as fast as possible, ...» (307).

${ }^{51}$ No en vano, Baretti opinaba que hubiera sido mejor que Dillon se encargara de la edición del Quijote de Bowle, como hemos señalado anteriormente. 
todo su religión. El hecho de ser católico le permite una visión más comprensiva que la que demostraron otros viajeros anteriores (Marino, 2014: 188), y para él los españoles son un pueblo acogedor, valiente, alegre, y con dotes para la reflexión moral y teológica (algo que para Dillon ejemplifica Quevedo). Sin embargo, no piensa tan bien del gobierno y de la Inquisición. Para él sin duda el lamentable estado de las carreteras tiene que ver con una «bad policy of government»(26), y se alegra de vivir en Inglaterra, donde la propiedad privada y las libertades individuales sí son respetadas. ${ }^{52}$ De nuevo su visión de la religión en España llama la atención por su tono moderado, en comparación con la imagen que se tiene en Europa en este momento. No obstante esto no impide que critique con decisión los procesos inquisitoriales, llegando incluso a ofrecer una traducción del auto de fe de Pablo de Olavide (1778) en la última de sus cartas. Aquí Dillon se compadece de este hombre de reconocido «knowledge and patriotism» (305), que «was some time ago taken up at Madrid, hurried away from his house, and confined in the dark prisons of the Inquisition, and after a long and painful imprisonment, was brought in the most humiliating manner before his judges» (306).

Todos estos asuntos orbitan, a veces con más desparpajo y naturalidad que otras, sobre la cuestión central del «origen y progreso» de la literatura española. El molde genérico de los libros de viaje le permite tratarlos de una forma orgánica y sin las ataduras formales a las que obligaría un tratado. Por eso caben, sin que sea posible reprochárselo, todo tipo de digresiones acerca de casi cualquier cosa que tenga que ver con España o la literatura. Además, en sí mismas las Letters también son un artefacto literario y retórico (recordemos las Lettres persanes de Montesquieu). De hecho, la habilidad literaria del caballero inglés pretende hacernos creer que la información sobre literatura emerge naturalmente del lugar en que se encuentra, esto es, que el recorrido histórico está determinado por el itinerario de su viaje, y no por la estructura de Velázquez, su fuente. Así, se habla de la poesía provenzal trovadoresca cuando se encuentra en Valencia, nos habla de la Escuela de Traductores y el Arcipreste de Hita cuando está en Toledo, donde ha podido ver el manuscrito, y se le ocurre hablar del Siglo de Oro porque «they happened last night to speak of the golden age of poetry in Spain» (158) en una tertulia a la que asistió. El marco ficcional sirve como excusa para su análisis literario, algo que está en la misma esencia del género de viajes.

En suma, las Letters de Dillon renuevan el panorama de los libros de viaje a España, interesándose por su literatura como no se había hecho antes. Son el texto en inglés que trata de forma más completa la tradición literaria española en su momento, y quizá en todo el siglo XVIII, sirviéndose para ello de una bibliografía actualizada. Pero además ocupan un lugar especial en el género por su actitud más comprensiva hacia la cultura española en general. Se puede comparar con Twiss, por ejemplo, que en sus Travels de 1776 hace un acopio de todo ese legado cultural y artístico español (aunque mucho más breve y superficial), pero desconfía de los españoles, e incluso muestra cierto desprecio. Como se apuntaba, la actitud más abierta de Dillon pueda deberse probablemente a la afinidad de credo, pero también a que no era el primer viaje que hacía a España, y a diferencia de otros de estos viajeros, Dillon conocía perfectamente la lengua. Es decir, si los viajeros ingleses intercedieron favorablemente en la imagen de lo español en Europa, como transición de los modelos franceses a los alemanes (Hönsch, 2000: 95-99), en este aspecto destaca Dillon particularmente. Por lo tanto, por su divulgación incomparable de la literatura española en lengua inglesa, y por su visión tolerante de España y su cultura, las Letters fueron un texto pionero y valioso para esa

${ }^{52}$ Hablando de un ataque que sufrió Mayans y su biblioteca por parte de los jesuitas: «Oh happy England! Where the property of individuals is sacred, and where the least violation of liberty, meets with a spirited and just resentment from the people» (36). 
construcción de la historia literaria española que se hace en el cambio de siglo XVIII a XIX, y en un diálogo entre nacionales y extranjeros.

Dillon y sus obras fueron conocidos en Europa, y otros trabajos suyos fueron traducidos a otras lenguas: sus Travels al alemán, ${ }^{53} \mathrm{o}$ su History of the Reign of Peter the Cruel (1788), fue traducida tan solo dos años después al francés. ${ }^{54}$ No tanto como los Travels, las Letters también fueron bien acogidas, como es de esperar de un género que tenía tanto éxito editorial. Sabemos, por ejemplo, que fue un texto importante para el poeta Robert Southey (Marino, 2014: 203), ${ }^{55}$ y también quienes se dedicaban a la historiografía literaria española en estos años la conocieron y valoraron. Uno de ellos fue el mismo Juan Andrés, que en el segundo tomo de su gran obra menciona a Dillon junto a Tomás Antonio Sánchez como autores que han tratado la figura de Juan Ruiz, Arcipreste de Hita (Andrés, 1782-1799: 63). Sin duda fue un texto de referencia para los hispanistas ingleses posteriores, como Bowring o Wiffen, y Thomasina Ross lo tiene en cuenta en su traducción de Bouterwek. ${ }^{56}$ También George Ticknor conoció las Letters y tuvo un ejemplar, ${ }^{57}$ aunque las subestimó al pensar que no ofrecían nada distinto de los Orígenes de Velázquez.

\section{EL ESSAI SUR LA LITTÉRATURE ESPAGNOLE (1810)}

En 1810, treinta años más tarde, aparece en París el Essai sur la littérature espagnole, editado por Jean-Barthélemy Lecouteulx de Canteleu (1746-1818). Este político francés es en realidad el único nombre que aparece en la portada del ensayo, publicado anónimamente. Sabemos que Lecouteulx también se dedicó a las finanzas, y que por entonces había logrado ocupar un puesto relevante en la sociedad parisina de la época. Su carrera se vio favorecida con el ascenso de Napoleón Bonaparte, y fue nombrado Conde del Imperio en 1804, además de ocupar el cargo de Presidente de la Administración central del departamento del Sena inferior. Durante esta trayectoria dejó algunos escritos e intervenciones parlamentarias que nos pueden dar una idea de sus intereses y ocupaciones políticas. ${ }^{58}$ Además, sabemos que pudo entablar relación con Pablo de Olavide en Francia (Perdices Blas), y que había leído los clásicos españoles y que también estaba familiarizado con el idioma.

Respecto a la cuestión de la autoría, la línea general ha sido atribuir la obra a Malmontais o Malmontet (Díaz-Plaja, Romero Tobar, Álvarez Rubio, Reyes Gómez), ${ }^{59}$ de quien en realidad no se tiene constancia de ningún tipo. La atribución comienza con el Atlas historique et chronologique des littératures anciennes et modernes (1831) de Adrien Jarry de Mancy, quien en su lista de «Principales obras a consultar sobre la historia de la literatura española» incluye el nombre de Malmontais junto al Essai: «Anonyme (Lecouteulx de Canteleu et Malmontais): Essai sur la littérature espagnole;

53 Dillon (1782), Reise durch Spanien, welche wichtige Beobachtungen aus der Naturgeschichte,..., aus Don Guillermo Bowles Einleitung, Leipzig.

${ }^{54}$ Mlle. Froidure de Rezelle (trad.) (1790), Histoire de Pierre le cruel, Paris, Briand.

${ }^{55}$ En una carta al editor de la Monthly Magazine (1796), Southey opina que estas cartas «will give the reader a good general view of the subject... His work has been the companion of my studies: I have derived pleasure and instruction from it, and have only to regret, that by not extending it, he has left a less able pen to attempt the supplement» (en Marino, 2014: 203).

${ }^{56}$ History of Spanish and Portuguese Literature, London, Boosey and sons, 1823.

${ }^{57}$ Whitney, 1879: 119. Vid. Marino, 2014: 194-195.

${ }^{58}$ Se puede ver en su página de la BNF:

$<$ http://catalogue.bnf.fr/rechercher.do?motRecherche=barth\%C3\%A9lemy+lecouteulx\&critereRecherche $=0 \&$ depart $=0 \&$ facetteModifiee $=0 \mathrm{k}>$.

${ }^{59}$ Vid. Álvarez Rubio, 2007: 99, n. 255. 
un petit volumen in- $8^{\circ}$; Paris, 1810. Resumé excellent» (Jarry de Mancy, 1831: 24). La referencia nada nos permite deducir del tal Malmontais ni de su participación en el texto, que además aparece citado como anónimo. Sin embargo, salvo Puibusque (1843), que insiste en el anonimato, la inmensa mayoría de los estudiosos atribuyeron el Essai a Malmontais: Quérard (tomo V, 1833), Lefranc (1843), Demogeot (1880) o Tronchon (1912). No obstante, Lefranc, junto con otros autores de repertorios bibliográficos del mismo siglo —-Brunet (1844), Rolland (1850), o Fastenrath (1874)—, le hacen compartir la autoría con Lecouteulx. En particular, Baret (1875) otorga un mayor peso a Lecouteulx en la redacción del Essai, aduciendo sus conocimientos de la tradición literaria española. El asunto no está nada claro.

A diferencia de las Letters, el Essai sí ha gozado de amplio reconocimiento como una de las primeras historias de la literatura española. Se encuentra en los repertorios bibliográficos (Reyes Gómez, 2010) y aparece ya mencionado tanto en los primeros trabajos canónicos sobre historiografía literaria (Díaz-Plaja, 1963: 138, n. 38) como en otros más actuales (Romero Tobar, 1996: 162, n. 26; 2010: 470). El estudio más extenso con el que cuenta es sin duda el de María del Rosario Álvarez Rubio en su volumen Historias de la literatura española en la Francia del siglo XIX (2007). Bajo el título de «un precursor de entresiglos» ofrece un capítulo sobre el ensayo francés que resulta ser el estudio más completo.

Por otro lado, se ha señalado que el Essai se escribe bajo las nuevas conexiones hispano-francesas que genera el reinado de José Bonaparte, y con el que florece un nuevo interés por España y su lengua en el país vecino. Para el autor, que piensa que la literatura española es desconocida en general, hay razones que justifican la aparición del ensayo:

Aujourd'hui qu'un long oubli peut leur rendre [a los textos y autores españoles] le charme de la nouveauté, et qu'il nous importe de nous familiariser avec la langue qui les a produits, j'essayerai d'indiquer les plus remarquables à l'attention des Amateurs des Belles Lettres, et de tracer un tableau de l'origine et des progrès de la poésie nationale en Espagne (Essai: 2).

El texto se presenta como una obra divulgativa que pretende paliar el desconocimiento de la literatura española en Francia. Ya antes, como hemos visto, se asomaron a este terreno Bricaire de la Dixmerie y Laborde; sin embargo, este ensayo es el primer trabajo en francés que exclusivamente pretende historiar la literatura española, llegando hasta el mismo siglo XVIII. El Essai abre un lustro fundamental para la difusión de la tradición literaria en Francia - con la inminente traducción francesa de Bouterwek, la historia de Sismondi y las traducciones de Schlegel—, situándose en un punto intermedio entre la valoración que de esta hacen los clásicos y la que traerá el Romanticismo. También viene a confirmar una visión francesa más amable de España, y parece asumir las defensas que los autores españoles de los ochenta y noventa han hecho de su literatura (Álvarez Rubio, 2007: 121). ${ }^{60}$

Presenta quizá la forma algo desfasada de una historia literaria del XVIII en el XIX, pero sin duda tiene el mérito de ofrecer la síntesis de toda una tradición literaria en una lengua que no contaba con ella (en este sentido es el «resumé excellent» que elogiaba Jarry de Mancy). Para ello se vale de autores españoles del XVIII, y principalmente de Velázquez, de quien también asume la periodización. Además, cita de

${ }^{60}$ «Así pues, este ensayo de vulgarización secunda los esfuerzos de los prestigiosos intelectuales españoles desde la primera mitad del XVIII por reintegrar la cultura española al canon europeo representado aún entonces por el centro francés, en trance de derrocamiento» (Álvarez Rubio, 2007: 121). 
forma frecuente a Sarmiento y Tomás Antonio Sánchez, de quienes se sirve especialmente para la literatura medieval. Aun así, en su tratamiento de las fuentes el Essai acaba siendo «un palimpsesto de préstamos y redacciones de épocas diversas» (Álvarez Rubio, 2007: 100). Ello lo demuestra que mientras conoce la actualidad literaria de Meléndez Valdés, Tomás de Iriarte, Ramón de la Cruz o Moratín, al final de su capítulo sobre la literatura del siglo XV habla de la Colección de Sánchez como si aún no se hubiera publicado, retrasando la redacción de este fragmento hasta unos treinta años antes. ${ }^{61}$

El ensayo fue bien acogido en su momento de publicación, como muestra un periódico parisino, el Journal des arts, des sciences et de la littérature, que le dedicó una reseña dividida en tres artículos, del 25 de mayo y 10 y 15 de junio de $1810 .{ }^{62}$ Para el redactor, «[1]a littérature espagnole est fort peu connue, et par cela même dédaignée en France», aunque «des nouvelles circomstances viennent de fixer l'attention de la France sur 1'Espagne» (Journal, 1810: 194), y hay autores que entonces se dedican a quitar el polvo a las obras españolas y recuerdan que en otro tiempo estuvieron por encima de las francesas. Y en este contexto justifica la aparición del Essai, al que concede el mérito de la oportunidad:

L'auteur s'est caché sous le voilé de l'anonime; mais l'ouvrage se recommande assez par lui même, sans avoir besoin d'un nom illustre dans les lettres; et, s'il a "dû beaucoup de son succès aux circonstances, il suffit, pour sa gloire, de dire qu'il le méritait. Plusieurs feuilles périodiques de Paris ont donné à cet Essai les éloges auxquels il avait droit; elles en ont rendu un compte fort détaillé (Journal, 1810: 194).

Sin embargo, en el artículo no deja de criticarse el Essai por omisiones que se consideran importantes, pero sobre todo por un exceso de atención a aspectos biográficos de los autores, lamentando que ese esfuerzo no se haya dirigido a explicar los méritos de las obras, o a incluir más fragmentos de ellas que permitan al lector conocer el valor que tienen. ${ }^{63}$ Un año después, en 1811, aparece una nueva reseña sobre un «Ensayo sobre la literatura española» publicado en París en 1810, que sin duda es nuestro Essai. Lo publica en la Gaceta de Sevilla Alberto Lista en dos números (2 y 9 de abril), y muestra las interesantes tensiones que se producen entre la visión de España del autor del Essai, para quien la poesía española se forja con la suma del carácter árabe, y la del propio Lista, que niega tal caso, pensando que el carácter nacional se forma con Carlos V, ya superada la presencia del elemento musulmán. ${ }^{64}$

61 «J'ai cité les productions les plus remarquables: un auteur moderne, le père D. TommasoAntonio Sanchez, dans le prospectus d'un ouvrage où il comptoit rassembler ceux des poètes castillans antérieures au quinzième siècle, annonce que sa collection sera composée des morceaux suivans dont j'ai indiqué la plus grand partie : le Poème du Cid Campeador, les poèmes de Gonzalo Berceo, la vie de $\mathrm{S}$. Ildefonse écrite par le bénéficier d'Ubeda; les poésies de Juan Ruys [...] avec quelques autres poëmes rares qu'il cherchoit encore» (Essai: 57).

${ }^{62}$ Reseña de gran interés para el Essai que ha pasado inadvertida por la crítica.

${ }^{63}$ Por tanto el redactor ve en el Essai un trabajo algo anticuado, con las carencias propias de las historias de la literatura dieciochescas, y le hace compartir mérito y culpa con Velázquez. «Au lieu de s'étendre, comme l'a fait l'auteur, sur des anecdotes biographiques, il nous semble qu'il aurait mieux fait de donner un aperçu général du génie même et du caractère particulier de la littérature espagnole, et d'y joindre quelques fragments remarquables, soit des poètes, soit des prosateurs»; «Luis de Velasquez [...] enfin il entre dans tous les détails où est entré son successeur. Plan, conduite, opinions, tout est semblable; et nous croyons joindre nos éloges à ceux qui ont été donnés à l'Essai sur la Littérature espagnole» (Journal, 1810: 198-199).

64 «[L]os españoles que describe Tito Livio tienen las mismas cualidades fundamentales en su carácter que los del tiempo de Carlos V y Carlos III», (en Martínez Torrón, 1993: 244). 
Además de las reseñas contemporáneas, los historiadores franceses de la literatura española que se sucedieron a lo largo del siglo XIX se encargaron de consolidar el Essai como uno de los primeros textos franceses en la materia. Ocurre desde Stapfer, el prologuista de la traducción de Bouterwek (1812), ${ }^{65}$ y más tarde con Puibusque (1843), ${ }^{66}$ Baret (1875) y Demogeot (1880), para que luego Tronchon (1912) reprochase al autor sus escasas palabras sobre el Cid.

\section{LAS LETTERS DE DILLON EN EL ESSAI}

El suspicaz redactor del Journal des arts, des sciences et de la littérature ya se preguntaba en 1810 por el motivo del anonimato del Essai, y a continuación sugería de forma velada la falta de originalidad del trabajo: «mais gardez-vous aussi de devenir esclaves: imitez, mais ne copiez pas. Que si vous traduisez, bornez-vous à l'estime réservée au traducteur, et ne cherchez point à surprendre, par de petites supercheries, la gloire qui appartient au titre d'inventeur» (Journal, 1810: 199). Unas líneas más tarde sigue discutiendo sobre el extendido hábito de copiar:

beaucoup se contentent de déguiser et d'habiller à la française ou à la mode quelques écrits ignorés ou quelqu'ouvrage composé dans une langue étrangère. Ils imitent, ce n'est pas un mal; tout ce qu'il y a de condamnable est le silence qu'ils gardent sur la source où ils ont puisé. Certes autrefois on en usait plus loyalement, et les écrivains mettaient une franchise admirable à citer les noms des auteurs célèbres ou obscurs à qui ils devaient ou leur sujet ou quelques traits heureux (Journal, 1810: 200).

Quizá aquí, desde el primer momento de la publicación de la obra, esté la primera referencia a la condición plagiaria del Essai. Sin embargo, ha habido una serie de lecturas que lo han acusado directamente de copiar las Letters de Dillon. Fue Tomasina Ross la primera en denunciarlo en su traducción de Bouterwek (1823):

The Essai sur la littérature espagnole, published in Paris in 1810, which appears to have been well received by the French public, is a gross plagiarism. It is, with some slight additions, merely the translation of an anonymous English work, entitled Letter from an English traveller in Spain, the epistolary mode being dropped, and the materials transposed for the purpose of concealing the theft (Ross, 1823: 7).

Pero no solo Ross da cuenta del hurto a Dillon. Dos años más tarde se habla del asunto en un artículo titulado «On Spanish literature», publicado en la revista The Kaleidoscope el 26 de abril de 1825 y compuesto de fragmentos del Essai traducidos al inglés; es por ello que el autor se ve obligado a descubrir el origen de sus fuentes, y con estas las del Essai: ${ }^{67}$

${ }^{65}$ Stapfer (1812: 43) considera que el autor se centra demasiado en aspectos biográficos: «car c'est plus leur solution et l'histoire de cette littérature en général, de son origine, de ses progrès et des révolutions qu'elle a subies qu'il faut y chercher, que des détails biographiques et une analyse étendue de ses productions».

${ }^{66}$ Puibusque (1843: 398) habla del Cancionero de Baena, recogido por Tomás Antonio Sánchez, que ni Bouterwek ni Sismondi pudieron consultar, y que sin embargo un autor francés, el del Essai, sí lo hizo al parecer, «vers 1808, dans la bibliothèque de l'Escurial, pendant l'occupation de notre armée».

${ }^{67}$ Efectivamente, es una traducción al inglés del Essai francés, luego la traducción de una traducción, debido seguramente al desconocimiento de la obra de Dillon, que entre los ingleses tuvo una menor difusión que el Essai como obra de consulta sobre la literatura española. 
We are indebted for much in the succeeding numbers to a little French work, Essai sur la Litterature Espagnole, Paris, 1810. But the greater portion of the Essai appeared in an English work published perhaps thirty years before, and now almost entirely unknown. Whoever is but moderately conversant with French literature, will not be surprised at such a theft, though it is one of the most impudent ever committed (Kaleidoscope, 1825: $363){ }^{68}$

También Palau recoge esta idea sobre el ensayo, que aparece en dos entradas de su Manual (1948-1980): bajo el nombre de Malmontais, y también bajo el de Dillon (IV, entrada 73963). ${ }^{69}$ No obstante, a pesar de estas referencias, nadie entró en detalle sobre la relación textual existente entre el Essai y las Letters, habiéndose solo mencionado que el primero es una traducción del segundo en la que básicamente se ha eliminado la forma epistolar. A continuación veremos que el asunto es en realidad algo más complejo.

Como antes señalábamos, hay indicios de que el Essai está compuesto por redacciones separadas en el tiempo que lo retrasan unos treinta años respecto a su fecha de publicación, de forma que todos los datos parecen confirmar que efectivamente no estamos ante un trabajo original. ${ }^{70}$ En realidad, con tan solo observar los índices del Essai y las Letters ya se verán coincidencias que llaman la atención: además de las cuatro époques idénticas y el primer capítulo sobre el «Origine et progrès de la poésie National en Castille», el Essai tiene un último capítulo («Sur la Bibliothèque de l'Escurial, les traductions des classiques grecs, latins et italiens, les Commentateurs et Prosateurs espagnols») con título muy parecido a la carta XIII de Dillon: «Remarks made in the library of the Escurial, on Spanish commentators, poetical translations of Greek and Latin classics, and italian authors». Finalmente, la identidad se hace notar en la redacción desde las primeras páginas dedicadas a presentar la lengua castellana: en la tercera página del Essai comienza una traducción al francés de las Letters que se corta, se amplía y se reescribe a lo largo de toda la obra:

La langue commune, en Espagne, s'appelle Langue Castillane ou Romance. C'est elle que l'on parle sur les théâtres et dans les universités. La ville de Tolède étoit regardée comme le lieu où on la parloit le plus purement, lorsque les monarques y faisoient leur résidence ; mais, aujourd'hui, Madrid luis a enlevé ces avantages. Elle est généralement répandue dans les deux Castilles, les provinces de Léon, d'Aragon, d'Estremadure, d'Andalousie, de Navarre, de Rioja, et dans les montagnes de Burgos [...] (Essai: 3).

The common language of Spain is called Castilian, or Romance. This is what is printed in books, spoken at court, in the universities, and generally in all polite circles. Toledo was the standard, when the residence of the monarchs; but now Madrid undoubtedly bears the palm. This is the language that prevails in the two Castiles, Leon, Aragon, Estremadura, Andalusia, Navarre, Rioja and the mountains of Burgos [...] (Letters: 6).

Una sencilla comparación de los textos demuestra que la traducción no se limita a ciertos lugares que podríamos mostrar aquí, sino que es general y su rastro fácil de

${ }^{68}$ El artículo continúa: «It would be no difficult matter to prove that the French writers are almost all plagiarists in a greater or less degree. Even Racine and Voltaire, names for which a Frenchman would fight, are notorious for plagiarism».

${ }^{69}$ En Fermín de los Reyes, 2010: 78.

${ }^{70}$ Por la referencia del Essai a la Colección de Sánchez como una obra que aún no se ha publicado (vid. n. 61). Sin embargo Dillon no hace nunca referencia a Sánchez, y esta anacronía se explica porque el fragmento proviene en realidad de Conti (1782), como veremos. 
seguir. $^{71}$ Podría pensarse que la similitud en las fuentes empleadas justifica este parecido. Esto es, si Dillon usa la misma estructura que Velázquez e incluso lo traduce y parafrasea, tal vez el autor del Essai hace lo mismo y de ahí la identidad entre ambos textos. La hipótesis la desmiente el que la información relativa a la historia de la lengua, tomada por las Letters de Mayans y Aldrete, también aparece idéntica en el ensayo francés. ${ }^{72}$ Tendríamos que suponer que ambos autores han consultado las mismas fuentes, han seleccionado exactamente el mismo contenido, y le han dado una misma redacción. Por fin, una serie de lecturas comunes en las Letters y el Essai que no aparecen en Velázquez terminan por descartar esta hipótesis. Por ejemplo, leemos en el Essai:

On attribue encore à Alfonse, l'introduction du papier dans l'Espagne chrétienne; mais il paroît que les Mahométans en connoissoient l'usage antérieurement, car Sarmiento assure qu'il a vu un papier manuscrit à la date de 1261. Je ne m'étendrai point davantage sur l'Histoire littéraire d'Alfonse (Essai: 49-50).

De la misma forma se expresa Dillon:

Alphonso is thought to have first introduced paper in Spain, at least amongst the Christians, supposing its use to have been known amongst the Mahometans: for Sarmiento mentions having seen a paper manuscript in 1261. I shall not, however, enter into further details relating to the works of this monarch (Letters: 126).

En Velázquez no hay referencias a esta supuesta introducción del papel en España por Alfonso X, y además la referencia a Sarmiento es cosecha de Dillon. Poco después el viajero irlandés presenta al Arcipreste de Hita y su manuscrito, para luego mencionar a Velázquez, de quien dice que ha sacado el resumen que ofrece a continuación: «therefore I shall confine myself to a specimen of a satyrical piece, as given by Velasquez» (Letters: 129). En el Essai nos encontramos exactamente con lo mismo: «j'essayerai cependant d'en faire connoître un fragment tel que Velasquez l'a publie» (Essai: 51$),{ }^{73}$ seguido del resumen de Velázquez. Estos y otros pasajes indican entonces que la fuente primaria del Essai son las Letters, y solo a través de ellas se sirve de los Orígenes.

Sin embargo, no podemos decir que todo el Essai sur la littérature espagnole sea una traducción verbatim (Marino, 2014: 203, n. 23), o que simplemente se elimine la parte epistolar de Dillon (Ross). Con el Essai se persigue el objetivo de dar a luz un trabajo - aunque con las limitaciones que tiene un estudio divulgativo- de corte científico, y para eso debe prescindir de todo el elemento literario del género de viajes, de las constantes digresiones sobre historia o carácter de los españoles, y recoger exclusivamente lo que tenga que ver con la historia literaria española. Pero también se deben reordenar esos materiales que en Dillon están dispersos, y por supuesto añadir otras informaciones cuando se crea oportuno. En este sentido, la «Introduction» de treinta páginas del Essai se corresponde con las cartas I-VII de Dillon, salvo la VI sobre la batalla de Almansa. Por tanto se nos presenta la lengua castellana en el contexto linguiístico peninsular, se habla de los autores hispanorromanos, de las invasiones goda y árabe, de autores árabes y judíos en Al-Ándalus, y para acabar la poesía «lemosina» y la gallego-portuguesa. Mientras en las Letters estos contenidos parecen coincidir con

\footnotetext{
${ }^{71}$ Vid., por ejemplo, Letters (19-25, 54-65) y Essai (7-10, 14-22).

${ }^{72}$ Vid. Essai (3-6) y Letters (6-11).

${ }^{73}$ A partir de ahora cito el Essai solo por el número de página para facilitar la lectura.
} 
sus viajes, en el texto francés sirven más claramente al propósito que tuvo Velázquez de trazar el mapa de las literaturas que han estado en contacto con la castellana y que la han influido. Pero además se añade un párrafo sobre la literatura de los judíos (12) y una reseña biográfica de «El enamorado Macías» (23-27), tomada al parecer de Sarmiento.

En realidad las páginas de esta introducción son sin duda las que más se ajustan a Dillon, y sí se pueden considerar prácticamente una traducción literal. Sin embargo, a medida que se va avanzando en la historia literaria española, los añadidos son más prolongados y frecuentes. Por eso la «Premier époque de la littérature espagnole» del segundo capítulo del Essai es bastante más completa que en Dillon. De la literatura medieval de los siglos XIII y XIV el inglés prácticamente solo presta atención a Alfonso X y el Arcipreste de Hita, además de mencionar los Milagros de Nuestra Señora de Berceo, y en una carta posterior hablar del Cid solo en su dimensión histórica y legendaria. Es aquí donde se acusa la lectura de Tomás Antonio Sánchez en el Essai - cuya Colección no se menciona en las Letters - , lo que le permite iniciar el capítulo con el Poema del Cid, del que destaca su «touchante naïveté» $(37)^{74}$ y del que ofrece además un fragmento de su entrada en Burgos en español y en francés (35-37). Al llegar a Gonzalo de Berceo, cree necesario hacer un inciso para explicar el verso alejandrino y en general la métrica española con el objetivo de «rendre familières quelques expressions que l'on pourra rencontrer dans la suite de l'ouvrage» (46). Esta explicación de la métrica (39-46) es mucho más extensa que la que hace Dillon, al recurrir a Sánchez y Bourgoing, del que cita un fragmento de su Tableau de l'Espagne moderne (1797) en el que se sorprende de la dificultad que tiene un extranjero en reconocer las rimas asonantes españolas. ${ }^{75} \mathrm{Al}$ llegar a Alfonso X, también añade un extraño párrafo al respecto del Libro del Tesoro ${ }^{76}$ y especula con la posibilidad de que la piedra filosofal fuera una alegoría de un poder sobrenatural del que gozó el monarca para gobernar (49). ${ }^{77}$ También incorpora un párrafo sobre Don Juan Manuel, ausente en las Letters, del que dice que «[1]es poèsies de ce prince sont en général, plus correctes que celle [sic.] de D. Alfonse» (51), y cita una de las moralejas de El conde Lucanor que confiesa no haber visto en ninguna otra obra. ${ }^{78}$ Por último, incluye aquí a Pedro López de Ayala y no en la segunda época (siglo XV) como hace Dillon, por considerar que produjo su obra a finales del XIV, y añade una reflexión sobre el desconocimiento que hay en Francia de la historia de España, según le da pie la «partialité condamnable» (56) de la Crónica de Pedro el Cruel de Ayala. A esto sigue un repaso de lo que ha tratado hasta el momento y las fuentes que ha usado (56-58) — destacando a Sarmiento y Sánchezen un intento por dotar a su texto de una mayor coherencia que Dillon.

\footnotetext{
${ }^{74}$ Esta idea sobre lo naïf del Poema del Cid, que no se suele mencionar en los comentarios de otros poemas épicos medievales europeos, se repite entre los críticos extranjeros de la época, algo que sería interesante estudiar en posteriores trabajos.

${ }^{75} \mathrm{El}$ autor francés trata los asuntos de métrica solo por encima, no como Dillon, que busca en los versos y estrofas castellanos sus equivalentes latinos (Letters: 116-118).

${ }^{76}$ Versión castellana de Li Livres dou trésor de Brunetto Latini. Vid. Pilar Lorenzo Gradín, 2016.

77 «Cette pierre philosophale, trouvée par D. Alfonse, n'auroit-elle pas été, de la part de cet homme au-dessus de son siècle, une allégorie sous laquelle il auroit voulu persuader à ses peuples et à ses voisins, qu'il avoit un pouvoir surnaturel? Son livre et ses chiffres magiques ne déguiseroient-ils pas de règles ou principes de gouvernement ou d'administration, plus particulièrement celle de finances, qui a été long-temps enveloppée en Europe, sous des formes mystérieuses? Dans ce sens, le roi D. Alfonse a pu dire qu'il avoit trouvé la pierre philosophale; et son maître, cet Egyptien d'Alexandrie, avoit pu lui donner la science d'une langue hiéroglyphique connue seulement de la classe appelée à gouverner les peuples» (48-49). Este párrafo lo cita Puibusque (1843: 385, 386), y lo compara con la opinión menos ingenua de Maury, que piensa que se trata solo de un juego retórico.

${ }^{78}$ «Non aventures mucho tu riqueza / per consejo del home que a pobreza» (50).
} 
También hay innovaciones en las páginas dedicadas a literatura del siglo XV. En primer lugar, se prescinde de algunos datos histórico-biográficos de autores y monarcas, así como de información sobre publicaciones y ediciones de las obras, y aunque no se añaden autores nuevos, sí que se amplían los ya existentes en Dillon. Así, cuando llega al Marqués de Santillana, el Essai incluye tres estrofas de sus Proverbios y cita dos poemas nuevos: «Un poëme sur la création du monde, [...] [et] un autre sur le combat naval qui se donna entre les Gênois d'une part, et les flottes combinées d'Aragon et de Navarre» (63). ${ }^{79}$ También escribe más detenidamente que Dillon sobre la Carta Prohemio (63) y sus indicaciones históricas sobre literatura, y finalmente sitúa al marqués en una escuela de «dantistas» (sic., 64) que identifica con los primeros poetas españoles del siglo XV influidos por la lírica italiana. Es Juan de Mena sobre quien más profundiza respecto a Dillon, en concreto una página sobre su Laberinto, «un des monuments principaux de la vieille poesie» (67). Por último, lo relativo a Jorge Manrique aparece más claro y algo ampliado en el Essai.

Sin duda el capítulo sobre la literatura del siglo XVI, la «Troisième époque de la littérature espagnole», es el más extenso y cuidado (72-122), e incorpora una cantidad considerable de nuevo material, junto con fragmentos de Boscán, Garcilaso, Hurtado de Mendoza, Fray Luis de León o Ercilla, que lo hace notablemente más completo que el de Dillon. Como en las Letters, Boscán, Garcilaso y Hurtado de Mendoza forman la tríada de la primera poesía de «l'âge d'or» español, pero aquí aparecen en un orden más lógico (Boscán, Garcilaso, Mendoza) que en el irlandés (Boscán, Mendoza, Garcilaso). En su explicación sobre la penetración de las formas italianas en la poesía española bajo la iniciativa de Boscán, se apoya en su Carta a la duquesa de Soma, donde se relata la famosa conversación con Navagero, y no lo compara con Petrarca como Dillon (161), sino con Horacio por «une profondeur de pensé, une justesse d'expression, un art de mêler ensemble le grave et le doux, de satisfaire à la fois l'esprit et la raison» (75). A continuación trata de Garcilaso, deteniéndose en sus églogas «remplies d'intérêt» (77), y ofreciendo varios fragmentos de la Égloga I que reviste de comentarios con los que pretende subrayar su valor. ${ }^{80}$ Sigue con Hurtado de Mendoza, de quien añade un largo fragmento de su Guerra de Granada para ilustrar que en su faceta de historiador estaba a la altura de Tácito y Salustio (89), y continúa con Herrera y luego Cristóbal de Castillejo en los mismos términos que Dillon. Sí que aporta bastante más al llegar a «Louis Ponce de León», en realidad haciendo referencia a Fray Luis de León. Como a Dillon, al autor del Essai le interesa que fuera «inhumainement persécuté par le SaintOffice» (92), pero además comenta la anécdota del «decíamos ayer» a la que tiene acceso por un biógrafo (Mayans probablemente; Álvarez Rubio, 2007: 111), y que le sirve para mostrar la «gravité flegmatique des espagnols de cet âge», para a continuación traducir fragmentos de la oda al Tajo. Después de Esteban de Villegas, Barahona de Soto, los hermanos Argensola y otros poetas que también están en las Letters, dedica varias páginas a la Araucana de Ercilla, distanciándose tanto de Dillon como de Velázquez, donde esta información aparece desplazada en otros capítulos. ${ }^{81}$ Recoge la opinión de Voltaire sobre el poema, igual que sus fuentes, pero muestra un análisis más sesudo y añade varios pasajes que comenta. En general, aunque coincide en algunos de los defectos que le ve su compatriota, opina que hay más cosas buenas que malas, y alaba el genio e imaginación de Ercilla, así como la elegancia en la mayoría de

\footnotetext{
${ }^{79}$ Probablemente se refiera a las Edades del mundo y la Comedieta de Ponza, respectivamente.

${ }^{80}$ Por ejemplo, considera ingeniosa y nueva la imagen fluvial con que se pretende reflejar la inconstancia de Galatea (79), y opina que la estancia final sería del gusto de Virgilio.

${ }^{81}$ Dillon lo incluye en su capítulo sobre la biblioteca del Escorial, mientras que Velázquez lo hace en su epígrafe sobre la epopeya española.
} 
los versos. A continuación el autor se asombra de que los autores españoles hayan destacado en gran parte también por su distinguido linaje, entre los cuales nombra al Marqués de Villena, Jorge Manrique, Garcilaso de la Vega y Hurtado de Mendoza. En su lista de poetas célebres quiere terminar con el Viaje al Parnaso de Cervantes siguiendo a Dillon, pero luego añade a Fray Luis de Granada y un fragmento de su Introducción a la fe para mostrar la literatura moral del siglo XVI, y habla de Mariana y Zurita para hacer lo mismo con la historiografía. También innova al detenerse en la persecución de Mariana y atacar la Inquisición con mayor ferocidad que Dillon: para el autor la censura excesiva embrutece el espíritu humano (120), y se muestra preocupado por este asunto porque dice haber escuchado recientemente justificaciones sobre la Inquisición. ${ }^{82}$ Concluye de nuevo sintetizando y cohesionando su texto, y añadiendo que en este siglo las lenguas española e italiana se podían ver «dans toute leur pureté, tandis que les langues anglaise et française étoient, pour ainsi dire, encore dans la barbarie» (122).

El capítulo cinco sobre el último periodo de la literatura española (siglos XVII y XVIII) es enteramente nuevo. De las veintitrés páginas que tiene, tan solo las dos primeras pertenecen a Dillon, en las que se achaca el «faux goût» del Barroco a la influencia italiana, y cuyos difusores españoles se reparten entre los que desvirtúan el teatro, los conceptistas y los culteranos. El autor del Essai va más allá en la crítica a Góngora, y muestra el primer cuarteto de «Con diferencia tal, con gracia tanta» junto con un fragmento de su romance del Manzanares como demostración de su lenguaje afectado. Góngora, a su juicio, encabezaba una «misérable espèce [de poetas] qui, dans le siècle précédent, n'eût été payée que du plus profond mépris» (126). Además, la información sobre literatura española del XVIII es totalmente ajena a Dillon. Aquí hay una previsible diferencia de opinión respecto a este siglo, para el inglés dominado por las «modas afeminadas de Versalles», y en el Essai presentado como una restauración del buen gusto gracias a la penetración de las luces de Europa. ${ }^{83}$ Este nuevo esplendor comenzaría con Mayans, de quien destaca especialmente su biografía de Cervantes. En un nivel parecido de admiración se encuentra Feijoo por su «saber universal» (129) y su lucha contra los «erreurs populaires», y añade un fragmento de la «Voz del pueblo», además de alabar su Teatro crítico universal por su erudición y «zéle infatigable à poursuivre la vérité» (133). También ofrece un fragmento de Fray Gerundio, del Padre Isla, al que sitúa en una misma tradición que a Quevedo (134). Más tarde da muestras de un conocimiento de una literatura más reciente al tratar del jesuita expulso Montengón, y con más esmero al hacerlo de Tomás de Iriarte y Meléndez Valdés, llamado el Anacreonte de España, pero a quien supera en «elevación» el padre Montengón (144). No puede dejar pasar el siglo XVIII sin alabar la poética de Luzán, y proponer la lectura complementaria del Parnaso español de Sedano para aplicar sus reglas a la que cree una buena colección de poemas en castellano (144). Por último, el autor destaca que en este siglo se han producido una multitud de «histoires littéraires de l'Espagne», entre las que cita a los hermanos Mohedano, Juan Andrés, Sempere y Guarinos y Lampillas, y donde no se mencionan sus propias fuentes. Toda esta información sobre el siglo XVIII proviene seguramente del Itinéraire descriptif de l'Espagne de Laborde (1808: 212251), donde se nombra a estos autores.

82 «Qu'on me pardonne cette digression contre les persécuteurs des Luis de Léon, des Quevedo, des Mariana. Une indignation dont je n'ai pas été maître et quelques tentatives faites récemment, sinon pour justifier, du moins pour excuser la rigidité du St. Office, m'ont entrainé au-delà des bornes que je me suis prescrites» (120-121).

${ }^{83}$ «Le bon goût a repris ses droits, et l'on s'apperçoit que quelques rayons de la lumière répandue dans le reste de l'Europe, ont percé à travers les Pyrénées» (127). 
Otro punto en el que vemos esa distinta ordenación del contenido en el Essai respecto a su fuente es en el capítulo sobre el teatro español. Aquí recaen todos los autores de drama que en Dillon estaban dispersos en los diversos periodos de la literatura española. Esto ocurre, por ejemplo, con Lope, cuyas noticias en las Letters se encontraban repartidas en varias cartas: la XI y la XII (tercer y cuarto periodo) por cronología, la XIV sobre el teatro español, y la XV, en la que incluye una reseña biográfica del Fénix. En el Essai, sin embargo, Lope de Vega y otros dramaturgos (Lope de Rueda, Calderón o Moratín) que se habían ignorado en sus respectivos periodos cronológicos, aparecen directamente en el capítulo sexto «Sur le Théâtre espagnol», evitando así caer en repeticiones.

Vemos, entonces, que el autor del Essai construye una versión de las Letters de Dillon más ampliada y organizada. Para ampliarla el autor recurre a una cantidad considerable de materiales procedentes de diversas fuentes, entre las que destaca Tomás Antonio Sánchez y su Colección (1779-1790), a la que parece recurrir especialmente en los capítulos dos y tres, sobre literatura medieval - junto con Sarmiento-. Sin embargo, hay otras fuentes ocultas intencionadamente, como se ha señalado con el Itinéraire (1808) de Laborde, de donde procede prácticamente todo lo referente al siglo XVIII español, y como también ocurre con la Colección de Giovan Battista Conti (1782-1790), a través de la cual parece haber accedido a Sánchez en algunos casos. Ya el hecho de que se le cite a la italiana («Tommaso-Antonio Sanchez», 57, 71) nos sugiere que hay una fuente italiana que media en el conocimiento de Sánchez, pero el parecido entre estos fragmentos del texto francés con la introducción de la obra de Conti acaban por demostrar esta influencia.

J'ai cité les productions les plus remarquables: un auteur moderne, le père $\mathrm{D}$. TommasoAntonio Sanchez, dans le prospectus d'un ouvrage où il comptoit rassembler ceux des poètes castillans antérieures au quinzième siècle, annonce que sa collection sera composée des morceaux suivants dont $\mathrm{j}$ 'ai indiqué la plus grand partie : le Poème du Cid Campeador, les poèmes de Gonzalo Berceo, la vie de S. Ildefonse écrite par le bénéficier d'Ubeda; les poésies de Juan Ruys archiprêtre de Hita, du Juif D. Santo, de Pedro Lopez de Ayala, de Juan Manuel auteur du comte Lucanor; l'histoire du comte Fernan Gonzalez; des vers de Pedro Gomez, avec quelques autres poèmes rares qu'il cherchoit encore (57).

Quanto agli altri autori, ed opere poetiche, che si riferiscono a' tempi, de' quali si è finora parlato, ecco ciò, che promette il dotto, e benemerito D.Tommaso Antonio Sanchez Bibliotecario di S. M. nella sua collezione di Poesie Castigliane anteriori al secolo XV: «I Poemi, che per ora vedranno la luce, avuto riguardo nell' ordine alla loro vera, o verisimile antichità, saranno i seguenti. Il Poema del Cid Campeador; le Poesie di D. Gonzalo di Berceo; la vita di S. Idelfonso scritta dal Benefiziato di Ubeda; le Poesie di Giovanni Ruiz Arciprete di Hita; quelle dell'Ebreo D. Santo; quelle di Pietro Lopez di Ayala; 1'istoria del Conte Fernando Gonzalez; alcuni versi di Pietro Gomez. Entreranno parimente in questa collezione, se ci riuscirà di farne opportunamente la scoperta, il Poema di Alessandro, i voti del Pavon, le Poesie di D, Giovanni Manuel autore del Conte Lucanor; e finalmente ogni altra Poesia... (Conti, 1782-1790: CXII, CXIV) ${ }^{84}$

${ }^{84}$ También se puede ver en los siguientes fragmentos: «Si l'on veut avoir des renseignements plus étendus sur l'origine et le progrès de la poésie castillane, j'engage les amateurs à lire l'Opuscule de Louis Velasquez sur les origines de la langue castillane, le premier tome des Euvres posthumes du P. Martin Sarmiento, Bénédictin, ayant pour titre: Memorias para la historia de la poesia y poetas españoles, et la collection déjà citée des poésies castillanes antérieures au quinzième siècle, par le $\mathrm{P}$. Tommaso Antonio Sanchez» (70-71). «Queste notizie intorno alla Poesia Castigliana dal suo principio fino al 
Esto nos indica que el Essai se construyó sobre una traducción de las Letters de Dillon, a la que se añadió información proveniente de, al menos, las fuentes que hemos citado. Una mano hábil, la del que podemos considerar autor del Essai, organizó estos materiales de una forma coherente y con cierto éxito, ${ }^{85}$ añadiendo especialmente el texto destinado a ensamblarlos, reescribiendo sus fuentes cuando creyó necesario, ${ }^{86}$ pero también mostrándose conocedor de la tradición literaria española, como indica el repaso anterior. No obstante, el resultado es una historia más completa que la de Dillon, y de haber citado sus fuentes poco habría que reprocharle de su «excellent resumé» (Jarry de Mancy, 1831: 24) de la tradición literaria española.

Respecto al autor que reúne todos estos contenidos bajo la forma de un ensayo, poco podemos saber. Sí podemos especular con cómo tuvo acceso a Dillon. En su History of the Reign of Peter the Cruel (1788), el irlandés menciona sus Letters como un «essay on the literature of Spain» (Letters: XIII). El acceso lo pudo tener el autor francés a través de la traducción de esta obra, ${ }^{87}$ donde las cartas de Dillon se mencionan como un «essai sur la littérature d'Espagne» (Letters: VI), de forma muy parecida al título de nuestro ensayo francés. También pudo mediar en el conocimiento de Dillon la traducción de Ortolani del Origine de Juan Andrés, donde se menciona al irlandés y su texto, como hemos visto. ${ }^{88}$ Por lo tanto lo único que sabemos a ciencia cierta del autor es que conocía el inglés y probablemente estaba familiarizado con el italiano (dada la referencia de Conti) y el español. Pudo ser el mismo Lecouteulx o — ¿por qué no?alguien llamado Malmontais, así como cualquier otro nombre que se nos escape. Lo que sí parece estar claro es que la elección del anonimato iba encaminada a protegerse de eventuales acusaciones de plagio que el autor ya preveía.

\section{CONCLUSIONES}

Estas páginas nos permiten llegar a una serie de conclusiones. En primer lugar, se constata el plagio a Dillon en el Essai sur la littérature espagnole (1810), como ya había señalado Thomasina Ross (1823), y hemos visto cómo se lleva a cabo: prescindiendo de lo epistolar de las Letters, pero también con considerables añadidos de otras fuentes (a veces también ocultas) y la reordenación de los elementos en busca de un formato más actualizado de una historia de la literatura. La manera de operar del autor del Essai nos permite ver cómo a principios del siglo XIX ha cambiado el paradigma genérico de las historias literarias. Esto es, esta nueva especie no tiene en su momento de nacimiento (segunda mitad del XVIII) un modelo estable, lo que permite que Dillon pueda incluir sus informaciones sobre literatura española en un libro de viajes. En el siglo XIX, sobre todo a partir de Bouterwek (1804), el género adquiere ya

terminare del secolo XV sono tratte per la maggior parte dall' opuscolo di D. Luigi Velasquez, sopra le Origini della Poesia Castigliana, dal primo tomo delle opere postume del P. F. Martin Sarmiento Monaco Benedettino, il di cui titolo è Memorie per la Storia della Poesia, e de' Poeti Spagnuoli, e dalla di sopra accennata Collezione delle Poesie Castigliane anteriori al secolo XV di D. Tommaso Antonio Sanchez Bibliotecario di S. M.» (Conti, 1782-1790: CXXXIV, CXXXVI).

${ }^{85}$ No podemos olvidar que se le pasaron algunas referencias temporales contradictorias, como veíamos antes.

${ }^{86}$ Por ejemplo, evita las constantes referencias de Dillon a poetas ingleses (como la comparación de Lope con Shakespeare), y lógicamente se distancia de él en sus juicios negativos de la literatura española del XVIII por su influencia francesa.

${ }^{87}$ Mlle. Froidure de Rezelle (trad.) (1790), Histoire de Pierre le cruel, Paris, Briand.

88 J. E. Ortolani (trad.) (1805), Histoire générale des sciences et de la littérature, Paris, Imprimerie Impériale. Traducción solo de los dos primeros tomos de la obra de Juan Andrés. 
la forma con que hoy lo conocemos, y el Essai, un texto al fin y al cabo de carácter divulgador, se encamina hacia esta forma definitiva al ser el más sobresaliente precursor de la historiografía literaria española en francés del siglo XIX, en la que luego destacan Sismondi (1813), Puibusque (1843), Baret (1875) o Demogeot (1880).

También hemos podido comprobar el destacado papel de los viajeros ingleses del XVIII en la difusión europea de la cultura española, y en particular las Letters de Dillon en el conocimiento de la tradición literaria. Su moderna visión de España y su interés por su literatura deberán esperar treinta años para verse igualados en Francia, lo que nos indica el desfase existente en distintos países al respecto de tal asunto. En este sentido, alemanes e ingleses toman la iniciativa en la revisión europea de lo español y su legado cultural en el siglo XVIII, adelantando ciertos aspectos de la visión romántica. Es interesante observar cómo esta nueva visión de la literatura española se construye en gran medida a partir de textos españoles, entre los que destacan singularmente los Orígenes (1754) de Velázquez: con versión alemana de Dieze (1769), introducido por Dillon en el mundo anglosajón (1781), y en el mundo francés gracias al Essai (1810). Junto a él también Sarmiento, Sánchez y Juan Andrés, entre otros, conforman un conjunto de fuentes que se encuentran de forma constante en las visiones extranjeras de la literatura española, probando que estas se construyen en un diálogo con nuestros eruditos nacionales.

Sin embargo, los autores extranjeros, aunque integran los datos y algunas apreciaciones críticas de las fuentes españolas, reinterpretan estas, elaborando así una visión propia de la literatura española que también varía en función de intereses ideológicos. En este contexto elaboran Dillon y el autor del Essai sus visiones, y aunque ambos acreditan el valor del legado literario español, le niegan un protagonismo en el presente — quizá de forma más atenuada en el ensayo - que se disputan entre Francia y Reino Unido. Lo español queda entonces relegado al pasado a través del exotismo que comienzan a introducir estos autores; por ejemplo, con una importancia sobredimensionada del componente árabe en la cultura española, como ocurre en Dillon, o aduciendo lo ingenuo o naïf de la literatura española, como veíamos en el Essai. Si el siglo XVIII expulsó el legado cultural español a la periferia de Europa, en las últimas décadas asistimos a una revalorización de este en unos términos que, sin embargo, no permite a los españoles reclamar una nueva posición en un presente que se les niega. Esta es la otra cara de esa visión más amable que los románticos construyeron de España, y que generó opiniones encontradas entre los mismos españoles. ${ }^{89}$

Por otro lado, todo esto no hace sino recordarnos que las historias literarias, herramienta importantísima para la confección de los cánones literarios nacionales, no dejan de ser elucidaciones variables de una misma realidad, y en muchos casos interesadas. Así, unos mismos datos están sujetos a múltiples interpretaciones al servicio de criterios ideológicos, haciendo también de la tradición literaria nacional un terreno de disputas políticas.

\section{OBRAS CITADAS}

\section{Fuentes primarias}

Andrés, Juan (1782-1799), Dell'origine, progressi e stato attuale d'ogni letteratura, Parma, Stamperia Reale.

Antonio, Nicolás (1672), Bibliotheca hispana nova, Roma, Nicolai Angeli Tinassii.

\footnotetext{
${ }^{89}$ Vid. el capítulo «La reacción española al mito romántico» de Andreu Miralles, 2016: 117-121.
} 
Antonio, Nicolás (1696), Bibliotheca hispana vetus, Roma, Antonii de Rubeis.

Baret, Eugène (1875), Observations sur l'Histoire de la littérature espagnole de M. Amador de los Ríos, Paris, Pedone-Lauriel.

Baretti, Giuseppe (1972), Opere scelte, 2 vols., Torino, Unione tipográfico-editrice torinese.

Baretti, Giuseppe (1786), Tolondron. Speeches to John Bowle about his edition of Don Quijote; Together with some account of Spanish literature, London, R. Faulder.

Brunet, Jacques Charles (1844), Manuel du libraire et de l'amateur de livres, tomo V, Paris, Silvestre.

Bouterwek, Friedrich (1804), Geschichte der Spanischen Poesie und Beredsamkeit, Göttingen, Rower.

Conti, Giovan Battista (1782-1790), Colección de poesías castellanas traducidas en verso toscano, Madrid, Imprenta Real.

Demogeot, Jacques (1880), Histoire des littératures étrangères dans leurs rapports avec le développement de la littérature française. Littératures méridionales, Paris, Hachette et Cie.

Dieze, Johann Andreas (1769), Geschichte der Spanischen Dichtkunst; aus dem Spanischen übersetzt und mit Anmerkungen erläutert, Göttingen, Victoriuus Bossiegel.

Dillon, John Talbot (1780), Travels through Spain, with a view to illustrate the natural history and physical geography of that kingdom, in a series of letters, London, G. Robinson.

Dillon, John Talbot (1781), Letters from an English traveller in Spain, in 1778, on the origin and progress of poetry in that kingdom, London, Baldwin.

Dillon, John Talbot (1788), The History of the Reign of Peter the Cruel, King of Castile and Leon, London, W. Richardson.

Esprit des journaux, François et étrangers (1790), Paris, Valade.

Fastenrath, Juan (1874), La Walhalla y las glorias de Alemania, Madrid, Estereotipía y Galvanopía de Aribau y Compañía.

Jarry de Mancy, Adrien (1831), Atlas historique et chronologique des littératures anciennes et modernes, Paris, Jules Renouard.

Journal des arts, des sciences et de la littérature (1810), vol. 29.

Kaleidoscope, or literary and scientific mirror (1825), vol. 5.

Laborde, Alexandre de (1808), Itinéraire descriptif de l'Espagne, Paris, H. Nicolle et Lenormant.

Lampillas, Francisco Javier (1778-1781), Saggio storico-apologetico della letteratura spagnuola contro le pregiudicate opinioni di alcuni moderni scrittori italiani, Genova, Presso F. Repetto.

Lecouteulx de Canteleu, Jean-Barthélemy (ed.) (1810), Essai sur la littérature espagnole, Paris, Charles Barrois.

Lefranc, Émile (1838-1844), Histoire élémentaire et critique de la littérature, renfermant, outre des details biographiques et des considerations générales sur les auteurs, l'examen analytique de leurs principaux ouvrages, Paris, Périsse.

López de Sedano, Juan José (1768-1778), Parnaso español, Madrid, Antonio de Sancha.

Luzán, Ignacio de (1737), Poética, Zaragoza, Francisco Revilla.

Masdeu, Francisco (1781-1787), Storia critica della cultura spagnuola, Foligno, Pompeo Campana.

Mariana, Juan (1719), Historia general de España, vol. 8, Lyon, Antonio Briasson.

Mayans y Siscar, Gregorio de (1737), Orígenes de la lengua española, Madrid, Juan de Zúñiga.

Montesquieu, Charles-Louis de Secondat, baron de (1831), Lettres persanes, Paris, Pourrat Fréres.

Puibuisque, Adolphe de (1843), Histoire comparé des littératures Espagnole et Française, Paris, G. A. Dentu.

Quérard, Joseph Marie (1827-1839), La France littéraire..., Paris, F. Didot père et fils.

Rodríguez Mohedano, Pedro y Rafael (1766-1791), Historia literaria de España desde su primera población hasta nuestros días, Madrid, Francisco Xavier García.

Rolland, J. F. (1850), Conseils pour former une bibliothèque, tomo III, Paris, Guyot Fréres. 
Ross, Thomasina (trad.; ed.) (1823), History of Spanish and Portuguese literature, Friedrich Bouterwek, London, Boosey and sons.

Sánchez, Tomás Antonio (1779-1790), Colección de poesías castellanas anteriores al siglo XV, Madrid, Antonio de Sancha.

Sarmiento, Martín (1775), «Memorias para la historia de la poesía, y poetas españoles», en Obras póstumas, Madrid.

Schlegel, August Wilhelm, (1814), Mme. Necker de Saussure (trad.), Cours de littérature dramatique, Paris, Paschoud.

Sismondi, J. C. L. Simonde de (1813), De la littérature du midi de l'Europe, Paris, Treutel et Würtz.

Staël Holstein, Mme de (1800), De la littérature considérée dans ses rapports avec les institutions sociales, Paris, Maradan.

Stapfer (ed.) (1812), Histoire de la littérature espagnole, Friedrich Bouterwek, Paris, chez Renard.

Velázquez, Luis José (2013) [1754], Orígenes de la poesía castellana, ed. Jesús Alejandro Rodríguez Ayllón, Málaga, Universidad de Málaga.

Whitney, James Lyman (1879), Catalogue of the Spanish Library and of the Portuguese Books bequeathed by George Ticknor to the Boston Public Library, Boston, Board of Trustees.

Bibliografía secundaria

Aguilar Piñal, Francisco (2016), Madrid en tiempos del «mejor alcalde», vol. IV, Sant Cugat, Arpegio.

Álvarez Barrientos, Joaquín (2004), «Nación e historia a mediados del siglo XVIII en España», en Leonardo Romero Tobar (ed.), Historia literaria/Historia de la literatura, Zaragoza, PUZ, pp. 101-114.

Álvarez Rubio, M. ${ }^{a}$ del Rosario (2007), Las historias de la literatura española en la Francia del siglo XIX, Zaragoza, PUZ.

Aullón de Haro, Pedro, Santiago Navarro Pastor y Jesús García Gabaldón (coords.) (2002), Juan Andrés y la teoría comparatista, Valencia, Biblioteca Valenciana.

Baasner, Frank (1995), Literaturgeschichtsschreibung in Spanien von den Anfangem bis 1868, Francfort del Meno, Klostermann.

Bacigalupo, Mario Ford (1978), «An Ambiguous Image: English Travel Accounts of Spain (1750-1787)», Dieciocho, 1, pp. 116-118.

Batten, Charles L. (1978), Pleasurable Instruction: Form and Convention in EighteenthCentury Travel Literature, Berkeley, University of California Press.

Bertrand, Jean-Joseph-Achille (1922), «Figures d'Hispanologues: Dieze, Bouterwek», Bulletin Hispanique, XXIV, pp. 343-360.

Bolufer Peruga, Mónica (2003), «Civilización, costumbres y política en la literatura de viajes a España en el siglo XVIII», Estudis, 29, pp. 255-300, 〈http://www.cervantesvirtual.com/nd/ark:/59851/bmcx06n5>.

Briesemeister, Dietrich (1984), «Entre irracionalismo y ciencia: los estudios hispánicos en Alemania durante el siglo XIX», Arbor, CXIX, pp. 105-122.

Cebrián, José (1996), «Historia literaria», en F. Aguilar Piñal (ed.), Historia literaria de España en el siglo XVIII, Madrid, Trotta-CSIC, pp. 513-592.

Chaunu, Pierre (1976), La España de Carlos V, Barcelona, Península.

Checa Beltrán, José (1994), «El debate literario español en el prólogo del romanticismo (17821807)», Revista literaria, tomo 56, $\mathrm{n}^{\circ} 112$, pp. 391-416.

Checa Beltrán, José (2004), «Debate literario y política», en Joaquín Álvarez Barrientos (coord.), Se hicieron literatos para ser políticos: cultura y política en la España de Carlos IV y Fernando VII, Cádiz, Universidad de Cádiz, pp. 147-166.

Checa Beltrán, José (2012), «Lecturas sobre la cultura española en el siglo XVIII francés», en José Checa Beltrán (ed.), Lecturas del legado español en la Europa ilustrada, Madrid, Iberoamericana-Vervuert, pp. 105-138. 
Comellas Aguirrezábal, Mercedes (2014), «Viajes y aprendizaje. Del Gran Tour dieciochesco al viaje romántico», en Eloy Navarro (ed.), Imágenes del mundo: literatura de viajes, ideología y representación, Universidad de Huelva, pp. 65-125.

Comellas Aguirrezábal, Mercedes (2017), «Argumentos poéticos para un debate político: la poesía del Siglo de Oro en los años del exilio romántico», e-Humanista. Journal of Iberian Studies, 37, pp. 143-171.

Comellas Aguirrezábal, Mercedes y Antonio Sánchez Jiménez (2018), «El lopismo inglés del siglo XVIII: Sir John Talbot Dillon (1739-1805) y William Hayley (1745-1820)», Edad de Oro, 37, en prensa.

D’Agostino, María (2014), «La Colección de poesías castellanas de Giovan Battista Conti: algunos ejemplos de traducción», en Begoña López Bueno (dir.), Entre sombras y luces, pp. 301-324.

Deacon, Philip (1978), «La historia interna de los Orígenes de la poesía castellana de Luis Joseph Velázquez», BOCES. XVIII, 6, pp. 65-82.

Deyermond, Alan (2004), «La difusión y recepción del Libro de Buen Amor desde Juan Ruiz hasta Tomás Antonio Sánchez: Cronología provisional», en Francisco Toro Ceballos y Bienvenido Morros (eds.), Juan Ruiz, Arcipreste de Hita, y el «Libro de Buen Amor», Alcalá la Real, Ayuntamiento Alcalá la Real, Centro para la Edición de los Clásicos Españoles, pp. 129-142.

Díaz-Plaja, Guillermo (1949), «Esquema historiográfico de la literatura española», en DíazPlaja (ed.), Historia general de las literaturas hispánicas (1949-1967), Barcelona, Barna.

Díaz-Plaja, Guillermo (1963), El estudio de la literatura, Barcelona, Sayma.

Étienvre, Françoise (2012), «Montesquieu y Voltaire: sus visiones de España», en José Checa Beltrán (ed.), Lecturas del legado español en la Europa ilustrada, Madrid, Iberoamericana-Vervuert, pp. 67-104.

Fabbri, Maurizio (2012), «No solo polémicas. La difusión de la cultura española en la Italia de la Ilustración», en José Checa Beltrán (ed.), Lecturas del legado español en la Europa ilustrada, Madrid, Iberoamericana-Vervuert, pp. 139-158.

Friederich-Stegmann, Hiltrud (2014), La imagen de España en los libros de los viajeros alemanes del siglo XVIII, Alicante, Universidad de Alicante.

González Roncero, María Isabel (2011), «Las zarzuelas de Antonio de Zamora (1665-1727). Índice y comentario», Dieciocho: Hispanic enlightenment, vol. 34, $\mathrm{n}^{\circ}$ 1, pp. 127-162.

Guerrero, Ana Clara (1990), Viajeros británicos en la España del siglo XVIII, Madrid, Aguilar.

Guillén, Claudio (1978), «Sobre el objeto del cambio literario», Analecta malacitana: Revista de la Sección de Filología de la Facultad de Filosofía y Letras, 1.2, pp. 255-291.

Gunia, Inke (2008), De la poesía a la literatura, el cambio de los conceptos en la formación del campo literario español del siglo XVIII y principios de XIX, Madrid, IberoamericanaVervuert.

Hönsch, Ulrike (2000), Wege des Spanienbildes im Deutschland des 18. Jahrhunderts: Von der Schwarzen Legende zum «Hesperischen Zaubergarten», Túbingen, Max Niemeyer.

Juretschke, Hans (2001), «Vida y obra de August Wilhelm Schlegel» (1946), y «Federico Schlegel. Una interpretación a la luz de la edición crítica de sus obras, con especial consideración de sus ediciones hispánicas» (1973), en Obras completas, Madrid, Editorial Complutense, pp. 25-45 y 669-736.

Krömer, Werner (1984), «El Romanticismo en España y en los países de lengua alemana (contactos y afinidades)», Arbor, CXIX, pp. 123-134.

Lorenzo Marín, Pilar (2016), «El diálogo entre tradiciones. El giro del Libro del Tesoro castellano», Medioevo romanzo, vol. 40, fasc. 1, pp. 119-135.

Maravall, José Antonio (1972), «Mentalidad burguesa e idea de la Historia en el siglo XVIII», Revista de Occidente, 107, pp. 250-286.

Marino, Nancy (2014), «John Talbot Dillon and His Letters on the Origin of Spanish Poetry: a Reconsideration», Dieciocho, 37, 2, pp. 187-210. 
Martín Ezpeleta, Antonio (2008), «El concepto de nación en la historiografía literaria española», en Leonardo Romero Tobar (ed.), Literatura y nación. La emergencia de las literaturas nacionales, pp. 433-466.

Martínez Torrón, Diego (1993), Ideología y Literatura en Alberto Lista, Sevilla, Ediciones Alfar.

McDonald, W.U. Jr. (1960), «Inglis' Rambles: A Romantic Tribute to Don Quixote», Comparative Literature, vol. 12, 1, pp. 33-41.

Miralles, Xavier Andreu (2016), El descubrimiento de España. Mito romántico e identidad nacional, Madrid, Taurus.

Navas Ruiz, Ricardo (2002), El canon poético en España de 1830 a 1837, Alicante, Biblioteca Virtual Miguel de Cervantes, <http://www.cervantesvirtual.com/obra-visor/laelaboracion-del-canon-en-la-literatura-espanola-del-siglo-xix-ii-coloquio-de-la-s-l-e-sxix-barcelona-2022-de-octubre-de-1999--0/html/p0000006.htm\#I_30_>.

O’Connor, Thomas Austin (2004), «El teatro de Agustín de Salazar y Torres (1636-1675)», en Ignacio Arellano Ayuso (coord.), Paraninfos, segundones y epígonos de la comedia del Siglo de Oro, pp. 181-187.

Ortas Durand, Esther (2006), Leer el camino. Cervantes y el Quijote en los viajeros extranjeros por España (1701-1846), Alcalá de Henares, Centro de Estudios Cervantinos.

Palau y Dulcet, Antonio (1948-1980), Manual del librero hispano-americano: inventario bibliográfico de la producción científica y literaria de España y de la América Latina desde la invención de la imprenta hasta nuestros días, con el valor comercial de todos los artículos descritos, Barcelona, A. Palau.

Pérez Isasi, Santiago (2006), «El nacimiento de la historia de la literatura nacional española, entre la Ilustración y el Romanticismo: la polémica calderoniana», en Dolores Fernández López y Fernando Rodríguez-Gallego (coords.), Campus Stellae. Haciendo camino en la investigación literaria, Santiago de Compostela, Universidade de Santiago de Compostela, pp. 529-538.

Pérez Isasi, Santiago (2013), «The Limits of "Spanishness" in Nineteenth-century Spanish Literary History», BHS, 90, pp. 167-187.

Pérez Magallón, Jesús (2012), «Apologías, identidad nacional y el desplazamiento de Europa a la periferia de la Europa "moderna"», en José Checa Beltrán (ed.), Lecturas del legado español en la Europa ilustrada, Madrid, Iberoamericana-Vervuert, pp. 13-40.

Pratt, Mary Louise (1992), Imperial Eyes: Travel Writing and Transculturation, Londres, 1992.

Pons-Rodríguez, Lola (ed.) (2008), Virtuosas e claras mugeres (1446), Burgos, Junta de Castilla y León, Instituto Castellano y Leonés de la Lengua.

Pozuelo Yvancos, José María (2007), «Canon e historiografía literaria», 1616: Anuario de la Sociedad Española de Literatura General y Comparada, vol. XI, Alicante, Biblioteca Virtual Miguel de Cervantes, <http://www.cervantesvirtual.com/obra/canon-ehistoriografa-literaria-0/>.

Pujante, Angel-Luis (2001), «Shakespeare Or/And...? The Spanish Counterpart in the Eighteenth and Nineteenth Centuries», en Boika Sokolova y Evgenia Pancheva (eds.), Renaissance Refractions. Essays in Honour of Alexander Shurbanov, Sofia, St. Kliment Ohridski University Press, pp. 157-169.

Reyes Gómez, Fermín de los (2010), Las historias literarias españolas. Repertorio bibliográfico (1754-1936), Zaragoza, PUZ.

Robertson, Ian (1988) [1976], Los curiosos impertinentes: viajeros ingleses por España desde la ascensión de Carlos III hasta 1855, Barcelona, Serbal.

Romero Tobar, Leonardo (1996), «La Historia de la Literatura Española en el siglo XIX (Materiales para su estudio)», El Gnomo: Boletín de estudios becquerianos, 5, pp. 151184.

Romero Tobar, Leonardo (2010), «El romanticismo y las primeras historias de las literaturas ibéricas», en F. Lafarga, L. Pegenaute y E. Gallén (eds.), Interacciones entre las literaturas ibéricas, Berna, Peter Lang, pp. 463-479.

Schrader, Ludwig (1991), «El interés por el mundo ibérico y los orígenes del hispanimo científico en los países de lengua alemana (siglo XIX)», en C. Strosetzski, J.-F. Botrel y 
M. Tientz (eds.), Actas del I Encuentro Franco-Alemán de Hispanistas, Fráncfort, Vervuert, pp. 1-18.

Strosetzski, Christopher (2002), «Paradigmas españoles en la Alemania del siglo XIX», en Miguel Ángel Vega Cernuda y Henning Wegener (eds.), España y Alemania: percepciones mutuas de cinco siglos de historia, Madrid, Editorial Complutense, pp. 79-93.

Turner, Katherine (2001), British Travel Writers in Europe, 1750-1800. Authorship, Gender and National Identity, Aldershot, Ashgate.

Turner, Katherine (2004), «Dillon, John Talbot», Oxford Dictionary of National Biography, $<$ http://www.oxforddnb.com.us.debiblio.com/view/10.1093/ref:odnb/9780198614128.0 01.0001/odnb-9780198614128-e-7658?rskey=2tgS1n\&result=1>.

Tronchon, Henri (1912), «Préromantisme allemand et français: Herder et Creuzé de Lesser adaptateurs du "Romancero del Cid"», Revue d'Histoire littéraire de la France, 19e Année, $n^{\circ} 4$, pp. 855-883.

Truman, R.W. (2003), «The Rev. John Bowle's Quixotic Woes Further Explored, Cervantes», Bulletin of the Cervantes Society of America, 23.2, pp. 9-43.

Urzainqui, Inmaculada (2004), «Hacia una teoría de la historia literaria en el siglo XVIII: competencias del historiador», en Leonardo Romero Tobar (ed.), Historia literaria/Historia de la literatura, Zaragoza, PUZ, pp. 59-68.

Urzainqui, Inmaculada (2007), «El Parnaso español en la historia literaria del siglo XVIII», Bullentin Hispanique, 109-2, pp. 643-684.

Villaverde Rico, María José y Francisco Castilla Urbano (dirs.) (2016), La sombra de la leyenda negra, Madrid, Tecnos. 